\title{
ANÁlise eSTRUTURAL da VEGETAÇão arbóREa EM TRÊS FRAGMENTOS florestais na Reserva Biológica de Poço das Antas, Rio de JANEIRO, B RASIL ${ }^{1}$
}

\author{
Solange de V. A. Pessoa ${ }^{2}$ \& Rogério R. de Oliveira ${ }^{3}$
}

\begin{abstract}
Resumo
(Análise estrutural da vegetação arbórea em três fragmentos florestais na Reserva Biológica de Poço das Antas, Rio de Janeiro, Brasil) Investigou-se aspectos do efeito da fragmentação e isolamento de habitats sobre a estrutura dos elementos arbóreos encontrados em três fragmentos florestais de diferentes tamanhos e formas, situados na Reserva Biológica de Poço das Antas, Silva Jardim, RJ. Foram demarcados transectos de $10 \mathrm{~m}$ de largura e comprimento variado de acordo com a extensão do fragmento, com orientações norte-sul e leste-oeste, subdivididos em parcelas contíguas de 10 × 25 m, sendo todos os indivíduos arbóreos com DAP $\geq 5 \mathrm{~cm}$ marcados e coletados dados de altura e diâmetro. Registraram-se 1.771 indivíduos, distribuídos em 43 famílias, 107 gêneros e 207 espécies. As áreas apresentam alta diversidade, onde as famílias Euphorbiaceae, Sapotaceae, Annonaceae, Moraceae e Nyctaginaceae configuram-se como as de maior valor de importância. A proporção elevada de espécies $(70 \%)$ em baixa densidade representa risco potencial de extinção para muitas populações locais, por outro lado a presença de espécies comuns em diferentes estágios de desenvolvimento, aliado ao arranjo espacial e a distância entre as áreas, permitindo a ação de polinizadores e dispersores atuam no sentido de minimizar este efeito.
\end{abstract}

Palavras-chave: estrutura da comunidade, Mata Atlântica, remanescente florestal, fragmentação.

\section{Abstract}

(Structural analysis of woody vegetation in three forest fragments in Poço das Antas Biological Reserve, Rio de Janeiro, Brazil) Aspects of the effect of fragmentation and isolation of habitats were investigated considering the structure of tree components, founded in three forest fragments of different size and shape located at Poço das Antas Biological Reserve, Silva Jardim, RJ. Transects of $10 \mathrm{~m}$ wide and as long as the distance between the edges, toward north-south and east-west and subdivided in contiguous plots of $10 \times 25 \mathrm{~m}$, were set and all tree individuals with $5 \mathrm{~cm} \mathrm{DBH}$ or more were tagged and data of height and diameter collected. Were recorded 1.771 individuals, being distributed within 43 families, 107 genera and 297 species. The areas have high diversity and the families Euphorbiaceae, Sapotaceae, Annonaceae, Moraceae and Nyctaginaceae presenting the higher important index values. The high proportion of species (70\%) in low density represents potential risk of extinction to many local populations and the fact that common species occurs at various stages of development just with the distance and spatial arrangement between the areas that permit the action of pollinators and dispersers, act toward to minimize this effect.

Key words: Atlantic Forest, community structure, forest remnants, fragmentation.

\section{INTRODUÇÃo}

A floresta tropical úmida localizada na costa atlântica brasileira, denominada Mata Atlântica vem sofrendo desde a época do descobrimento do Brasil intenso processo de desmatamento e fragmentação. Atualmente, no estado do Rio de Janeiro, os maiores fragmentos florestais podem ser observados apenas nas vertentes das cadeias montanhosas da Serra do Mar localizadas, em sua maioria, acima de $500 \mathrm{~m}$ de altitude (Tanizaki-Fonseca \& Moulton 2000). Restrita, no estado, apenas a $19 \%$ de sua área original é constituída em sua maioria por remanescentes de florestas secundárias em diferentes estágios de regeneração (Fundação S.O.S. Mata Atlântica 2002).

Artigo recebido em 02/2005. Aceito para publicação em 11/2005.

${ }^{1}$ Parte da Dissertação de Mestrado do primeiro autor no curso de Ciências Ambientais e Florestais, UFRRJ.

${ }^{2}$ Instituto de Pesquisas Jardim Botânico do Rio de Janeiro, Rua Pacheco Leão 915, 22460-030, Rio de Janeiro, RJ, Brasil. spessoa@jbrj.gov.br

${ }^{3}$ Pontifícia Universidade Católica do Rio de Janeiro, Dept ${ }^{\circ}$ de Geografia, Rua Marques de S. Vicente 225, 22453-900, Rio de Janeiro, RJ, Brasil. rro@geo.puc-rio.br 
Na região da planície litorânea do estado do Rio de Janeiro, o processo de fragmentação data desde os primórdios da colonização quando se intensificaram as intervenções antrópicas nesta paisagem, em especial aquelas relacionadas à implantação de atividades agrícolas, extrativistas e pastoris. Atualmente, a paisagem desta região está representada por remanescentes florestais de tamanhos variados, isolados e, em sua maioria, altamente perturbados e inseridos em amplas extensões de áreas campestres. À semelhança das florestas estacionais semideciduais do interior do estado de São Paulo constituem exemplo do processo de fragmentação (Nascimento et al. 1999), imersos que estão como ilhas de vegetação em meio a uma paisagem desestruturada.

Nas últimas duas décadas diversos estudos destes remanescentes foram efetuados, (Guedes 1988; Silva \& Nascimento 2001; Borém \& Oliveira-Filho 2002; Rodrigues 2004), com um significativo volume de trabalhos conduzidos na Reserva Biológica de Poço das Antas (Scarano et al. 1997; Guedes-Bruni 1998; Silva Matos et al. 1998a, 1998b; Neves 1999; Vieira \& Pessoa 2001; Pereira \& Mantovani 2001; Souza \& Martins 2002; Moraes et al. 2002), formada por um conjunto de remanescentes das florestas de morros e pequenos morrotes e terras baixas que originalmente recobriam a planície costeira. Nesta Reserva, o local de realização deste estudo, a fragmentação e subseqüentes transformações na paisagem ocorreram em decorrência da derrubada de áreas florestais para uso como pastagem ou pequena agricultura à época das fazendas e ao alagamento e drenagem de áreas como resultado da construção da Represa de Juturnaíba.

Com a fragmentação de habitats duas mudanças fundamentais são introduzidas: em contraste com a vegetação original, os fragmentos são descontínuos e geralmente de área muito reduzida e os organismos que persistem no fragmento são expostos às condições de um ecossistema vizinho diferente. $\mathrm{O}$ que tem sido chamado efeito de borda (Murcia 1995). Uma série de alterações bióticas e abióticas surge nestes remanescentes, normalmente resultando em mudanças na estrutura e composição da vegetação, que podem levar a um aumento das taxas de recrutamento e de mortalidade dos indivíduos arbóreos (Williams-Linera 1990, Laurence et al. 1998) e a variações na densidade e na área basal de indivíduos localizados, principalmente, nas áreas de borda em relação às áreas do interior do fragmento (Williams-Linera 1990; Murcia 1995). Alterações na distribuição de espécies de plantas e animais e nas interações entre elas, a exemplo de predação, competição, herbivoria, polinização biótica e dispersão de sementes também são verificadas (Lovejoy et al. 1986; Saunders et al. 1991; Aizen \& Feinsinger 1994; Murcia 1995).

Além disso, a fragmentação florestal pode ocasionar altas taxas de extinção (Bawa 1990; Aizen \& Feinsinger 1994) e quando a fragmentação resulta no isolamento genético total do habitat isolado, cada fragmento isolado torna-se demograficamente independente, podendo ocorrer extinção local (Templeton et al. 1990; Turner \& Collet 1996) provocando, portanto, significativa redução da diversidade biológica.

Diversos estudos apontam a influência da área total do fragmento, da idade, do histórico de perturbação, do grau de isolamento e da qualidade da matriz influenciando a intensidade e amplitude das variações provocadas pela fragmentação (Saunders et al. 1991; Turner 1996, Laurence et al. 1998, Mesquita et al. 1999). Fragmentos menores apresentando diferenças de composição e estrutura em relação a fragmentos maiores, via de regra, menos expostos a fatores de perturbação (Laurence 1997).

Neste trabalho pretende-se contribuir para um melhor conhecimento e entendimento dos efeitos da fragmentação e isolamento de habitats sobre a estrutura e diversidade dos 
elementos arbóreos de fragmentos de mata. Para tanto são investigadas as variações na estrutura e diversidade de três fragmentos de tamanho e forma diferentes.

\section{Material e Métodos}

Os três fragmentos florestais estudados encontram-se na Reserva Biológica de Poço das Antas próximos à área de influência da Represa de Juturnaíba, situado no limite sudeste da Reserva. A Reserva, localizada na porção central da planície costeira do estado do Rio de Janeiro, na região conhecida como baixada de Araruama, encontra-se entre as latitudes $22^{\circ} 30^{\prime}$ e $22^{\circ} 35^{\prime} \mathrm{S}$ e as longitudes $42^{\circ} 14^{\prime}$ 'e $42^{\circ} 19^{\prime} \mathrm{W}$ (Fig. 1). Os fragmentos estudados fazem parte de um conjunto de oito remanescentes de florestas sobre pequenas elevações, situados em extensa planície e relativamente isolados, sem corredores de vegetação interligandoos, distando entre si cerca de $60 \mathrm{~m}$ (área I e III), 280 m (área I e II) e 400 m (área II e III) (Fig. 2). A construção da represa de Juturnaíba, iniciada em 1984, implicou em modificações drásticas na paisagem, alterando o sistema de águas da região, facilitando a propagação de incêndios, provocando o desaparecimento das florestas sobre a planície de inundação, que cederam lugar a campos aluviais tornando completamente aberto o ambiente vizinho às florestas sobre os morrotes (Pessoa 2003). Segundo a administração da Reserva, o

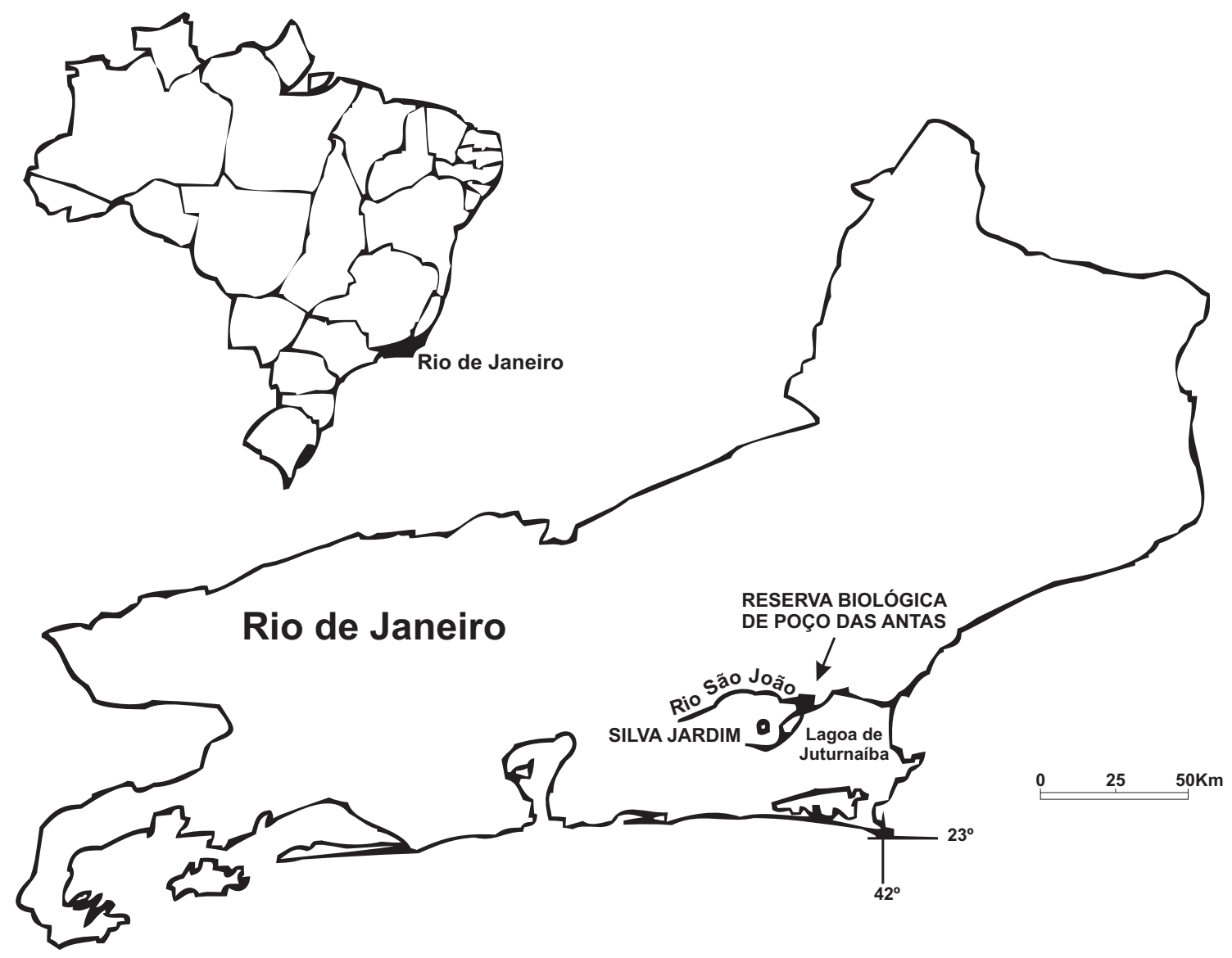

Figura 1 - Localização da Reserva Biológica de Poço das Antas, Rio de Janeiro (Fonte: Programa Mata Atlântica/JBRJ). 
primeiro incêndio que afetou a região das áreas estudadas ocorreu em dezembro de 1984, seguindo-se outros em 1986, 1991, 1993, 1997, 2000 e 2002, todos coincidindo com a estação seca. Os três últimos afetaram as áreas em estudo em suas bordas e com graus diferenciados de penetração e danos para o interior.

Segundo a classificação de Veloso et al. (1991), esta planície é ocupada pela Floresta Ombrófila Densa, com a formação Submontana ocorrendo nos dissecamentos do relevo montanhoso. Sua topografia é predominantemente de planície, apresentando pequenos morros e morrotes arredondados que podem atingir até $200 \mathrm{~m}$ de altitude, separados, muitas vezes, por áreas baixas aluviais periodicamente alagadas na estação das chuvas (Takisawa 1995).

Em cada um dos fragmentos foram implantados dois transectos de $10 \mathrm{~m}$ de largura e comprimento variado, de acordo com a extensão do fragmento, com orientações nortesul e leste-oeste, subdivididos em parcelas

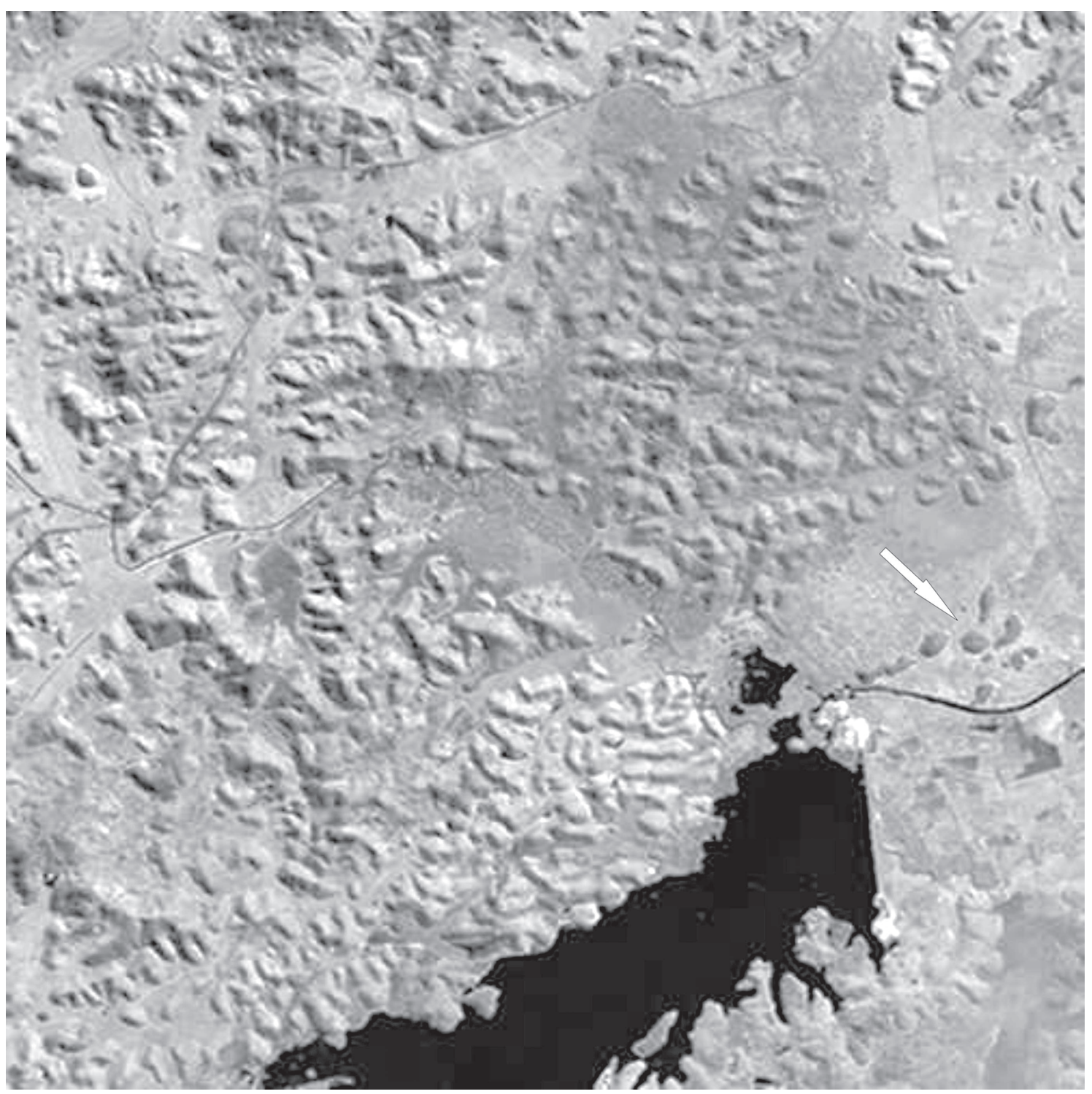

Figura 2 - Localização dos três fragmentos estudados na Reserva Biológica de Poço das Antas, RJ. (Miranda \& Coutinho, 2004) 
contíguas de $10 \times 25 \mathrm{~m}$. O método de transecto foi escolhido de forma a incluir na amostragem a maior quantidade possível da heterogeneidade florístico-estrutural existente em cada um dos fragmentos. No fragmento I (1,35 ha), os transectos mediram $125 \mathrm{~m}$ na direção leste-oeste e $100 \mathrm{~m}$ na direção nortesul, totalizando 9 parcelas $\left(2.250 \mathrm{~m}^{2}\right)$ no fragmento II (6,65 ha), $400 \mathrm{~m}$ na direção lesteoeste e $175 \mathrm{~m}$ na direção norte-sul, perfazendo 23 parcelas $\left(5.750 \mathrm{~m}^{2}\right)$ e no fragmento III $(9,34$ ha), $325 \mathrm{~m}$ em ambas as direções, em um total de 26 parcelas $\left(6.500 \mathrm{~m}^{2}\right)$. Todos os indivíduos com diâmetro a altura do peito $(1,30 \mathrm{~m}) \geq 5$ $\mathrm{cm}$ foram marcados, coletados e mensurados dados referentes à altura e diâmetro. A presença de árvores mortas ainda em pé foi incluída na amostragem.

Para identificação do material botânico, segundo o sistema de classificação de Cronquist (1988), utilizou-se consulta à especialistas, a literatura e à coleção do herbário do Instituto de Pesquisas Jardim Botânico do Rio de Janeiro (RB), onde encontra-se depositado o material testemunho. Os materiais cuja identificação ao nível de espécie ainda não foi possível foram categorizados como morfoespécies.

$\mathrm{Na}$ análise fitossociológica foram empregadas as fórmulas apresentadas por Mueller-Dombois \& Ellenberg (1974) para densidade, frequiência e dominância e valor de importância (VI). A estimativa da diversidade foi obtida utilizando-se o índice de diversidade de Shannon (Magurran 1988) e no cálculo da equabilidade (J) utilizou-se a fórmula de Pielou (1975, apud Magurran 1988).

Os parâmetros fitossociológicos foram calculados com o programa FITOPAC (Shepherd 1994). Na elaboração dos histogramas de freqüência de distribuição dos indivíduos por classe de diâmetro e por classe de altura, o intervalo de classe (IC), em cada uma das situações e para cada uma das espécies consideradas, foi calculado segundo Spiegel (1970, apud Felfili \& Silva-Junior 1988).

\section{Resultados e Discussão}

Nas três áreas foram amostrados 1.771 indivíduos, relacionados a 207 espécies, 43 famílias e 107 gêneros. Os fragmentos I, II e III apresentaram respectivamente 64 espécies, 239 indivíduos vivos e 69 indivíduos mortos ainda em pé; 107 espécies, 468 indivíduos vivos e 81 mortos e 151 espécies, 1.064 indivíduos vivos e 71 mortos. Os valores de densidade foram de 1.062, 813 e 1.636 ind./ha, enquanto os valores de área basal foram de 5,38, 13,24 e $20,07 \mathrm{~m}^{2} / \mathrm{ha}$ para as áreas I, II e III, respectivamente.

No que tange à densidade, seria esperado encontrar valores próximos para as áreas II e III, tendo em vista a semelhança em termos de área levantada. Meffe et al. (1997) afirmam que áreas maiores suportam populações maiores em relação a áreas menores, por estas proporcionarem condições bióticas e abióticas diferenciadas. Os valores encontrados para a área III corroboram esta afirmativa. $\mathrm{O}$ menor valor encontrado na comunidade II pode ser a expressão de perturbações mais intensas provocadas pelos incêndios passados e recentes, portanto em resposta à intensidade da perturbação e ao tempo decorrido entre os incêndios e desde o último. Dificuldades ou mesmo impedimento à regeneração de algumas espécies podem estar ocorrendo, como resultado de alterações drásticas em fatores bióticos e abióticos destas comunidades. Silva Matos et al. (1998) utilizando critério de inclusão diferente (DAP $\geq 10 \mathrm{~cm}$ ) relacionaram as variações encontradas entre as densidades às diferenças microclimáticas (velocidade do vento, umidade do ar, temperatura) observadas nestes fragmentos, sendo a ação do vento mais determinante para o fragmento II. Da mesma forma, a intensidade e o tempo decorrido, podem ter influenciado no valor obtido para o menor fragmento (área I). Os valores encontrados parecem indicar que as relações entre densidade e perturbação podem ser algo mais complexas do que o sugerido por Laurence et al. (1998) e Williams-Linera 
(1990), que encontraram um aumento na densidade em fragmentos pequenos. Possivelmente perturbações menos intensas possam significar aumento da densidade.

Silva \& Nascimento (2001) sugerem que baixos valores de área basal possam ser reflexo do grau de perturbação da área. À exceção da área I, o menor fragmento, os valores de área basal foram semelhantes aos obtidos em estudos de outras matas de planície com histórico de perturbação (13,8 e $24,4 \mathrm{~m}^{2} / \mathrm{ha}$ - Neves, $1999 ; 15 \mathrm{~m}^{2} / \mathrm{ha}$ - Silva \& Nascimento, 2001; $18 \mathrm{~m}^{2} / \mathrm{ha}-\mathrm{M}$. T. Nascimento (dados não publicados, apud Silva \& Nascimento, 2001); 26,1 $\mathrm{m}^{2} / \mathrm{ha}$ Borém \& Ramos, 2001; 23,1 m²/ha - Borém \& Oliveira-Filho, 2002. E são muito inferiores ao encontrado por Sztutmam \& Rodrigues (2002) (39,3 $\left.\mathrm{m}^{2} / \mathrm{ha}\right)$ para floresta de morrote em Pariquera-Açu, São Paulo, uma das maiores áreas de floresta contínua em bom estado de conservação para esta formação. Desta forma, os valores encontrados sugerem que estes podem estar relacionados tanto às perturbações decorrentes da fragmentação (Mesquita et al. 1999; Laurence et al. 2002), normalmente ocasionando a morte dos indivíduos de maiores diâmetros, quanto aos incêndios pretéritos. $\mathrm{O}$ valor alcançado para a área II possivelmente reflete a influência do diâmetro atingido por um de seus elementos $(109 \mathrm{~cm})$.

A ocorrência de indivíduos mortos em pé foi proporcionalmente maior nas áreas I e II, com $29 \%$ e $17,3 \%$ respectivamente, sendo ainda visíveis, em muitos indivíduos de ambas as áreas, os sinais dos danos causados pelo incêndio ocorrido pouco antes do início dos trabalhos. Na área III foram encontrados 71 indivíduos mortos ou $6,7 \%$ do total de indivíduos amostrados. Os dados levantados, exceto os observados na área III, mostramse superiores aos alcançados para outros trechos da Reserva $(10,3 \%$ e $11 \%$ - Neves 1999) e para outras áreas de mata de planície (4,08\% - Guedes, $1988 ; 9,7 \%$ - Silva \& Nascimento 2001), todas sujeitas a alguma forma de perturbação. Embora estudos apontem que a fragmentação e o efeito de borda aumentam a mortalidade dos elementos arbóreos (Williams-Linera 1990; Tabanez et al. 1997; Laurence et al. 2002), os altos valores observados nas áreas I e II devem ser creditados, em grande parte, à ação do fogo, evidenciado pelo fato da maioria dos indivíduos mortos apresentarem troncos completamente ou parcialmente queimados.

No que se refere à ocorrência de caules múltiplos ou ramificações abaixo de $1,30 \mathrm{~m}$ a altura do peito, foram encontrados na área I 7 indivíduos (2,9\%), distribuídos em 6 espécies, na área II, 53 indivíduos (11,3\%), distribuídos em 25 espécies e na área III 22 indivíduos (2\%), distribuídos em 15 espécies. No total, 38 espécies apresentaram mecanismo de rebrota como uma estratégia para se manter na comunidade, auxiliando desta forma a cicatrização de trechos abertos na floresta, seja pela via antrópica (fogo) ou pela via natural (vento, senescência, etc). A relevância da regeneração por rebrota em espécies arbóreas da floresta tropical é apontada por Ewel (1977), salientando Grime (1979, apud Castellani 1986), que o crescimento por rebrota mostra-se mais vantajoso sobre o desenvolvimento a partir de sementes, tendo em vista que o primeiro não necessita alocar recursos para a formação de raízes. Embora, para as unidades em estudo, a ocorrência de caules múltiplos pareça estar relacionada tanto a eventos antrópicos como naturais, este fato também pode ser uma característica ligada à espécie ou à própria floresta (Dunphy et al. apud Sá 2002).

Os dados obtidos para abundância de famílias, considerando aquelas que perfazem $75 \%$ dos indivíduos amostrados, indicam que são os elementos das famílias Euphorbiaceae, Annonaceae e Sapotaceae, e em menor escala os das famílias Moraceae e Nyctaginaceae os que exercem um papel mais preponderante na caracterização da fisionomia das três unidades estudadas (Fig. 3). Na área I observase o predomínio da família Euphorbiaceae, 
cujos 110 indivíduos perfazem $46 \%$ do total de indivíduos amostrados, fato ocasionado pela grande incidência da espécie Senefeldera verticillata. Para a área II, as famílias Euphorbiaceae (75 indivíduos), Ulmaceae (49), Nyctaginaceae (44), Annonaceae (36), Moraceae (30), Bignoniaceae (22) e Arecaceae (22) se sobressaem perante as demais. Nesta área, as espécies $S$. verticillata, Trema micrantha, Guapira areolata e G. opposita, Annona cacans, Helicostyles tomentosa, Sparattosperma leucanthum e Astrocaryum aculeatissimum contribuem para a dominância de suas respectivas famílias. A área III apresenta um quadro semelhante à área $\mathrm{I}$, com apenas duas famílias, Euphorbiaceae e Annonaceae, contribuindo com $49 \%$ do total de indivíduos amostrados, destacando-se que os 405 indivíduos de Euphorbiaceae representam 38\% deste total. Ressalta-se a contribuição das espécies $S$. verticillata e Anaxagorea dolichocarpa, respectivamente para a abundância destas famílias. Rubiaceae (97 indivíduos), Moraceae (63), Sapotaceae (55), Leguminosae (46) e Myrtaceae (38) formam as demais famílias que contribuem com quantitativos menores de elementos e perfazem $28 \%$ dos indivíduos amostrados. A presença destacada da família Ulmaceae na área II, sinaliza uma maior ocorrência de fatores de perturbação nesta área, pois a espécie que a representa é considerada característica de estádios iniciais do processo sucessional (Gandolfi et al. 1995).

Considerando o valor de importância das diferentes famílias presentes nas três áreas amostradas e referenciando somente aquelas famílias que totalizam cerca de $75 \%$ do valor total de importância, verifica-se que as famílias Euphorbiaceae, Sapotaceae, Leguminosae, Annonaceae, Lauraceae, Moraceae, Nyctaginaceae, Myrtaceae, Apocynaceae, Ulmaceae, Bignoniaceae, Arecaceae, Sapindaceae, Asteraceae, Flacourtiaceae, Boraginaceae, Meliaceae e Rubiaceae figuram entre as mais importantes. Uma comparação com outros estudos realizados nas florestas desta região indica que a maioria das famílias importantes para as áreas estudadas estão entre as mais importantes nestes estudos, embora exista uma variação de posição destas famílias no ranking de valor de importância (Guedes 1988; Guedes-Bruni 1998; Borém \& OliveiraFilho 2002; Rodrigues 2004).

Os dados apresentados na Figura 4 demonstram que Euphorbiaceae, Sapotaceae, Annonaceae, Moraceae e Nyctaginaceae
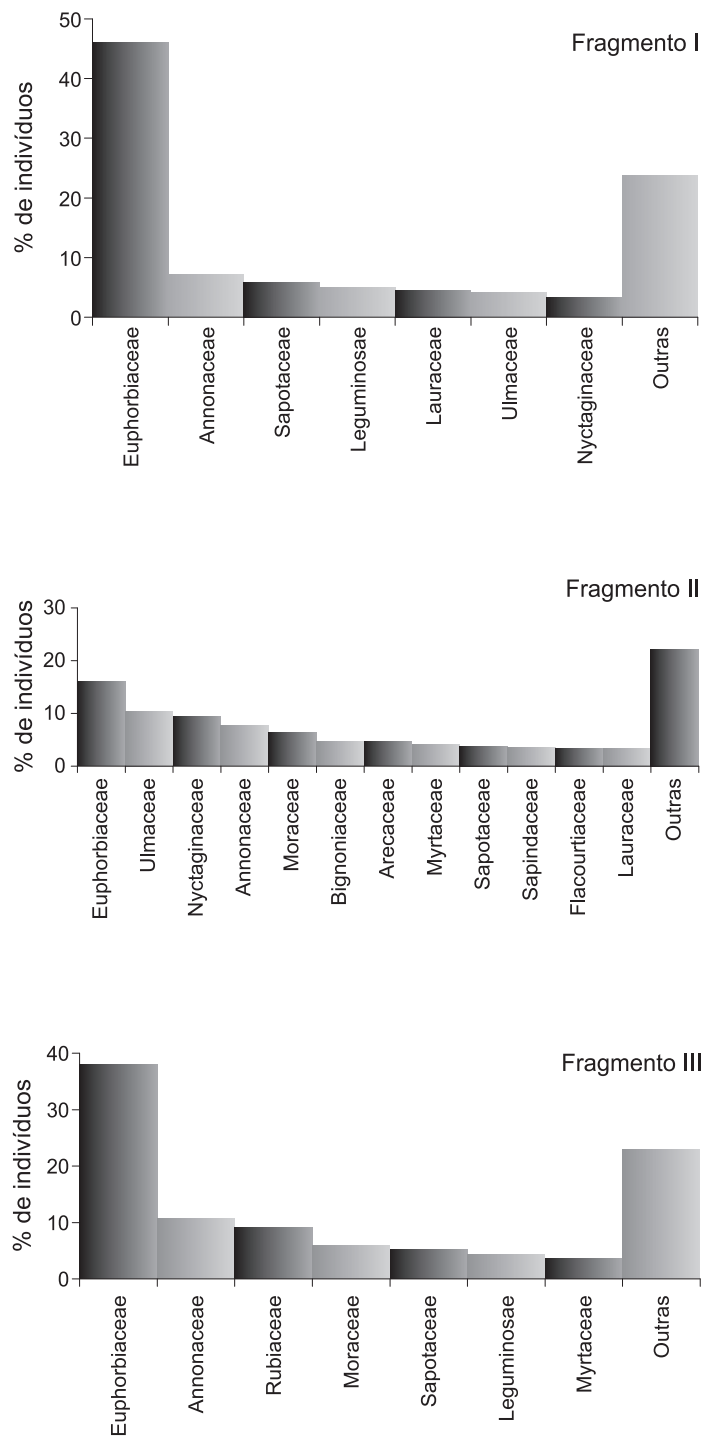

Figura 3 - Distribuição do percentual de indivíduos com DAP maior ou igual a $5 \mathrm{~cm}$ por família botânica em três fragmentos florestais amostrados na Reserva Biológica de Poço das Antas, RJ. Fragmento I - 1,35 ha; Fragmento II - 6,65 ha e Fragmento III - 9,34 ha. 
apresentam-se em destaque nas três áreas, resultado já obtido para o parâmetro abundância por família. Estes resultados demonstram que embora determinadas famílias possam caracterizar estas florestas, variações locais nas condições edáficas, topográficas, climáticas e fatores de perturbação podem contribuir para a presença destacada de determinadas famílias, fato que corrobora a proposição de Rodrigues (2004) de que a estrutura da vegetação seja uma responda a fatores abióticos locais.
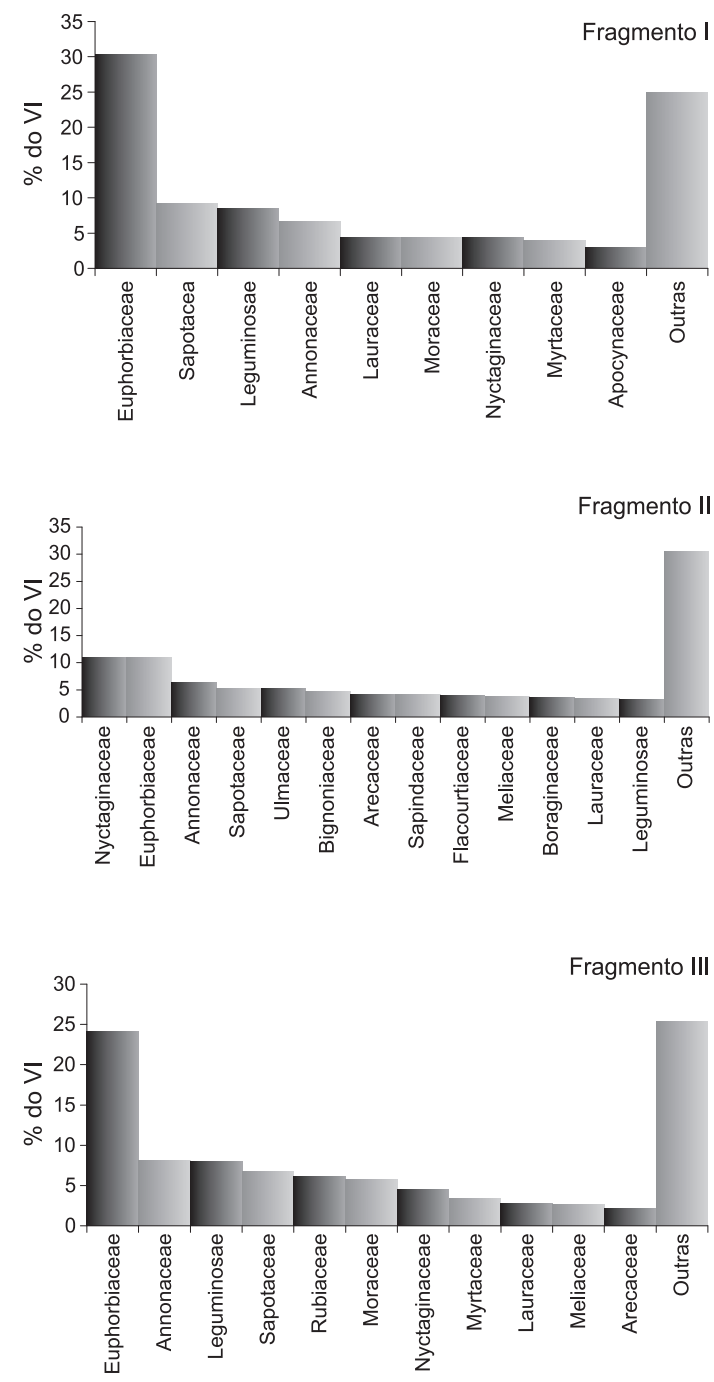

Figura 4-Distribuição percentual dos valores de importância (VI) por família botânica em três fragmentos florestais amostrados na Reserva Biológica de Poço das Antas, RJ. Fragmento I - 1,35 ha; Fragmento II - 6,65 ha e Fragmento III - 9,34 ha.
Da análise das espécies no que tange ao seu valor de importância (Tabs. 1, 2 e 3), observa-se uma variação entre os dez elementos florísticos de maior expressão para cada uma das unidades levantadas, como resultado ora da densidade destes componentes, fato mais frequiente, ora da dominância. $\mathrm{Na}$ área I destacam-se $S$. verticillata, Pogonophora schomburgkiana, Pera glabrata, Copaifera trapezifolia, $A$. dolichocarpa, Ecclinusa ramiflora, $G$. opposita, Balizia pedicellaris, Tetraplandra leandri. e T. micrantha. Diferentemente das demais, $P$. glabrata e $C$. trapezifolia estão bem posicionadas devido a seus valores de dominância relativa $(8,76 \%$ e $6,76 \%$, respectivamente). Para a área II sobressaemse $S$. verticillata, $T$. micrantha, Andradaea floribunda, A. cacans, A. aculeatissimum, G. opposita, S. leucanthum, H. tomentosa, G. areolata e Cordia sellowiana e à exceção de $S$. verticillata, $T$. micrantha e $A$. floribunda, as demais não apresentam grandes variações entre os valores de densidade e dominância. Na área III, as espécies que individualmente mais contribuem são S. verticillata, A. dolichocarpa, Actinostemon verticillatus, Mabea piriri, Faramea truncata, $H$. tomentosa, $E$. ramiflora, Pterocarpus rohrii, G. opposita e A. aculeatissimum. Para as espécies $M$. piriri, H. tomentosa, E. ramiflora e $G$. opposita, seus valores de densidade e dominância influenciam igualmente no valor de importância total obtido.

Ao compararmos estes resultados com outros trabalhos para florestas desta região (Guedes 1988; Guedes-Bruni 1998; Neves 1999; Borém \& Oliveira-Filho 2002; Rodrigues, 2004) observamos que somente $S$. verticillata, A. aculeatissimum, S. leucanthum, E. ramiflora, $H$. tomentosa e $G$. opposita são citadas. Isto sugere que à exceção das espécies acima mencionadas, as áreas estudadas devem ser consideradas importantes para a manutenção das demais espécies, como também apresentam condições mais propícias à sua ocorrência. 
Tabela 1 - Parâmetros fitossociológicos das espécies amostradas no Fragmento I na Reserva Biológica de Poço das Antas, RJ, ordenadas segundo o valor de importância (VI), sendo N= número de indivíduos; $\mathrm{DA}=$ densidade absoluta $(\mathrm{N} / \mathrm{ha}) ; \mathrm{FA}=$ freqüência absoluta $(\%)$; DoA $=$ dominância absoluta $\left(\mathrm{m}^{2} / \mathrm{ha}\right)$; $\mathrm{DR}=$ densidade relativa $(\%) ; \mathrm{FR}=$ frequiência relativa $(\%) ; \mathrm{DoR}=$ dominância relativa $(\%)$.

\begin{tabular}{|c|c|c|c|c|c|c|c|c|}
\hline Espécies & $\mathbf{N}$ & DA & FA & DOA & DR & FR & DoR & VI \\
\hline Senefeldera verticillata (Vell.) Croizat & 93 & 413,3 & 88,89 & 4,7220 & 38,91 & 6,67 & 19,73 & 65,31 \\
\hline Pogonophora schomburgkiana Miers ex Benth. & 10 & 44,4 & 55,56 & 0,8591 & 4,18 & 4,17 & 3,59 & 11,94 \\
\hline Pera glabrata (Schott) Baill. & 1 & 4,4 & 11,11 & 2,0966 & 0,42 & 0,83 & 8,76 & 10,01 \\
\hline Copaifera trapezifolia Hayne & 2 & 8,9 & 22,22 & 1,6170 & 0,84 & 1,67 & 6,76 & 9,26 \\
\hline Anaxagorea dolichocarpa Sprague \& Sandwith & 10 & 44,4 & 44,44 & 0,2625 & 4,18 & 3,33 & 1,1 & 8,61 \\
\hline Ecclinusa ramiflora Mart. & 5 & 22,2 & 44,44 & 0,7137 & 2,09 & 3,33 & 2,98 & 8,41 \\
\hline Guapira opposita (Vell.) Reitz & 6 & 26,7 & 55,56 & 0,3427 & 2,51 & 4,17 & 1,43 & 8,11 \\
\hline Balizia pedicellaris (DC.) Barneby \& J. W. Grimes & 3 & 13,3 & 33,33 & 1,0245 & 1,26 & 2,5 & 4,28 & 8,04 \\
\hline Tetraplandra leandri Baill. & 5 & 22,2 & 44,44 & 0,5756 & 2,09 & 3,33 & 2,4 & 7,83 \\
\hline Trema micrantha (L.) Blume & 10 & 44,4 & 33,33 & 0,1745 & 4,18 & 2,5 & 0,73 & 7,41 \\
\hline Manilkara aff. bella Monach. & 2 & 8,9 & 22,22 & 0,9910 & 0,84 & 1,67 & 4,14 & 6,64 \\
\hline Tapirira guianensis Aubl. & 1 & 4,4 & 11,11 & 1,1581 & 0,42 & 0,83 & 4,84 & 6,09 \\
\hline Duguetia pohliana Mart. & 4 & 17,8 & 44,44 & 0,2364 & 1,67 & 3,33 & 0,99 & 5,99 \\
\hline Pouteria reticulata (Eng.) Eyma & 2 & 8,9 & 22,22 & 0,8006 & 0,84 & 1,67 & 3,35 & 5,85 \\
\hline Aspidosperma spruceanum Benth. ex Müll. Arg. & 3 & 13,3 & 33,33 & 0,3906 & 1,26 & 2,5 & 1,63 & 5,39 \\
\hline Lecythis lurida (Miers) S. A. Mori & 3 & 13,3 & 33,33 & 0,3433 & 1,26 & 2,5 & 1,43 & 5,19 \\
\hline Micropholis guyanensis (A.DC.) Pierre & 2 & 8,9 & 22,22 & 0,5662 & 0,84 & 1,67 & 2,37 & 4,87 \\
\hline Cordia trichoclada DC. & 4 & 17,8 & 33,33 & 0,0885 & 1,67 & 2,5 & 0,37 & 4,54 \\
\hline Aniba firmula (Nees \& Mart. ex Ness) Mez & 3 & 13,3 & 33,33 & 0,0938 & 1,26 & 2,5 & 0,39 & 4,15 \\
\hline Garcinia gardneriana Miers ex Planch. \& Triana & 4 & 17,8 & 22,22 & 0,1843 & 1,67 & 1,67 & 0,77 & 4,11 \\
\hline Esenbeckia grandiflora Mart. & 5 & 22,2 & 11,11 & 0,2741 & 2,09 & 0,83 & 1,15 & 4,07 \\
\hline Eriotheca pentaphylla (Vell.) K. Schum. & 2 & 8,9 & 22,22 & 0,3542 & 0,84 & 1,67 & 1,48 & 3,98 \\
\hline Annona cacans Warm. & 3 & 13,3 & 22,22 & 0,2527 & 1,26 & 1,67 & 1,06 & 3,98 \\
\hline Virola gardneri (A.DC.) Warb & 2 & 8,9 & 11,11 & 0,5185 & 0,84 & 0,83 & 2,17 & 3,84 \\
\hline Tovomita glazioviana Engl. & 2 & 8,9 & 22,22 & 0,2995 & 0,84 & 1,67 & 1,25 & 3,75 \\
\hline Brosimum sp. & 1 & 4,4 & 11,11 & 0,5529 & 0,42 & 0,83 & 2,31 & 3,56 \\
\hline Guapira areolata (Heirmert) Lundell & 2 & 8,9 & 22,22 & 0,2511 & 0,84 & 1,67 & 1,05 & 3,55 \\
\hline Helicostylis tomentosa (Poepp. \& Endl.) Rusby & 2 & 8,9 & 22,22 & 0,1268 & 0,84 & 1,67 & 0,53 & 3,03 \\
\hline Lauraceae sp.1 & 2 & 8,9 & 22,22 & 0,0886 & 0,84 & 1,67 & 0,37 & 2,87 \\
\hline Sorocea guilleminiana Gaudich. & 2 & 8,9 & 22,22 & 0,0850 & 0,84 & 1,67 & 0,36 & 2,86 \\
\hline Aspidosperma discolor A.DC. & 2 & 8,9 & 22,22 & 0,0749 & 0,84 & 1,67 & 0,31 & 2,82 \\
\hline Inga capitata Desv. & 2 & 8,9 & 22,22 & 0,0643 & 0,84 & 1,67 & 0,27 & 2,77 \\
\hline Astrocaryum aculeatissimum (Schott) Burret & 2 & 8,9 & 22,22 & 0,0547 & 0,84 & 1,67 & 0,23 & 2,73 \\
\hline Albizia polycephala (Benth.) Killip ex Record & 1 & 4,4 & 11,11 & 0,3442 & 0,42 & 0,83 & 1,44 & 2,69 \\
\hline Swartzia apetala var. apetala R.S. Cowan & 2 & 8,9 & 22,22 & 0,0383 & 0,84 & 1,67 & 0,16 & 2,66 \\
\hline Ocotea divaricata (Nees) $\mathrm{Mez}$ & 2 & 8,9 & 22,22 & 0,0331 & 0,84 & 1,67 & 0,14 & 2,64 \\
\hline Ocotea aff. notata (Nees \& Mart. ex Ness) Mez & 1 & 4,4 & 11,11 & 0,3311 & 0,42 & 0,83 & 1,38 & 2,64 \\
\hline Sapotaceae sp.3 & 1 & 4,4 & 11,11 & 0,3247 & 0,42 & 0,83 & 1,36 & 2,61 \\
\hline Brosimum guianense (Aubl.) Huber & 2 & 8,9 & 11,11 & 0,2231 & 0,84 & 0,83 & 0,93 & 2,6 \\
\hline Eugenia dichroma Berg & 1 & 4,4 & 11,11 & 0,3058 & 0,42 & 0,83 & 1,28 & 2,53 \\
\hline Hirtella hebeclada Moric. ex DC. & 1 & 4,4 & 11,11 & 0,2737 & 0,42 & 0,83 & 1,14 & 2,4 \\
\hline Erythroxylum cincinnatum Mart. & 2 & 8,9 & 11,11 & 0,1484 & 0,84 & 0,83 & 0,62 & 2,29 \\
\hline Casearia arborea (Rich.) Urb. & 2 & 8,9 & 11,11 & 0,1318 & 0,84 & 0,83 & 0,55 & 2,22 \\
\hline Hyeronima oblonga (Tul.) Müll. Arg. & 1 & 4,4 & 11,11 & 0,2217 & 0,42 & 0,83 & 0,93 & 2,18 \\
\hline Cathedra rubricaulis Miers & 1 & 4,4 & 11,11 & 0,1767 & 0,42 & 0,83 & 0,74 & 1,99 \\
\hline Myrtaceae sp.1 & 1 & 4,4 & 11,11 & 0,1399 & 0,42 & 0,83 & 0,58 & 1,84 \\
\hline Licania aff. kunthiana Hook. f. & 1 & 4,4 & 11,11 & 0,1300 & 0,42 & 0,83 & 0,54 & 1,79 \\
\hline Ouratea olivaeformis Engl. & 2 & 8,9 & 11,11 & 0,0287 & 0,84 & 0,83 & 0,12 & 1,79 \\
\hline Myrtaceae sp.7 & 1 & 4,4 & 11,11 & 0,1195 & 0,42 & 0,83 & 0,5 & 1,75 \\
\hline Simaba floribunda A. St.-Hil. & 1 & 4,4 & 11,11 & 0,1118 & 0,42 & 0,83 & 0,47 & 1,72 \\
\hline Parinari excelsa Sabine & 1 & 4,4 & 11,11 & 0,0974 & 0,42 & 0,83 & 0,41 & 1,66 \\
\hline
\end{tabular}




\begin{tabular}{|c|c|c|c|c|c|c|c|c|}
\hline Espécies & $\mathbf{N}$ & $\mathbf{D A}$ & FA & DOA & DR & FR & DoR & VI \\
\hline Copaifera langsdorfii Desf. & 1 & 4,4 & 11,11 & 0,0962 & 0,42 & 0,83 & 0,4 & 1,65 \\
\hline Urbanodendron verrucosum (Nees) $\mathrm{Mez}$ & 1 & 4,4 & 11,11 & 0,0808 & 0,42 & 0,83 & 0,34 & 1,59 \\
\hline Erythroxylum cuspidifolium Mart. & 1 & 4,4 & 11,11 & 0,0785 & 0,42 & 0,83 & 0,33 & 1,58 \\
\hline Licania octandra (Hoffmanns ex Roem. \& Schult.) Kuntze & 1 & 4,4 & 11,11 & 0,0430 & 0,42 & 0,83 & 0,18 & 1,43 \\
\hline Sapotaceae sp.2 & 1 & 4,4 & 11,11 & 0,0422 & 0,42 & 0,83 & 0,18 & 1,43 \\
\hline Protium heptaphyllum (Aubl.) Marchand & 1 & 4,4 & 11,11 & 0,0378 & 0,42 & 0,83 & 0,16 & 1,41 \\
\hline Myrtaceae sp.3 & 1 & 4,4 & 11,11 & 0,0308 & 0,42 & 0,83 & 0,13 & 1,38 \\
\hline Ocotea elegans $\mathrm{Mez}$ & 1 & 4,4 & 11,11 & 0,0291 & 0,42 & 0,83 & 0,12 & 1,37 \\
\hline Urbanodendron aff. bahiense (Meisn.) Rohwer & 1 & 4,4 & 11,11 & 0,0218 & 0,42 & 0,83 & 0,09 & 1,34 \\
\hline Sapotaceae sp.1 & 1 & 4,4 & 11,11 & 0,0181 & 0,42 & 0,83 & 0,08 & 1,33 \\
\hline Faramea multiflora A. Rich. ex DC. & 1 & 4,4 & 11,11 & 0,0161 & 0,42 & 0,83 & 0,07 & 1,32 \\
\hline Marlierea dimorpha Berg & 1 & 4,4 & 11,11 & 0,0122 & 0,42 & 0,83 & 0,05 & 1,3 \\
\hline Swartzia apetala var. glabra (Vogel) R.S. Cowan & 1 & 4,4 & 11,11 & 0,0094 & 0,42 & 0,83 & 0,04 & 1,29 \\
\hline
\end{tabular}

Tabela 2 - Parâmetros fitossociológicos das espécies amostradas no Fragmento II na Reserva Biológica de Poço das Antas, RJ, ordenadas segundo o valor de importância (VI), sendo $\mathrm{N}=$ número de indivíduos; $\mathrm{DA}=$ densidade absoluta $(\mathrm{N} / \mathrm{ha}) ; \mathrm{FA}=$ freqüência absoluta $(\%)$; DoA= dominância absoluta $\left(\mathrm{m}^{2} / \mathrm{ha}\right)$; $\mathrm{DR}=$ densidade relativa $(\%) ; \mathrm{FR}=$ frequiência relativa $(\%) ; \mathrm{DoR}=$ dominância relativa $(\%)$.

\begin{tabular}{|c|c|c|c|c|c|c|c|c|}
\hline Espécies & $\mathbf{N}$ & DA & FA & DoA & DR & Fr & DoR & VI \\
\hline Senefeldera verticillata (Vell.) Croizat & 53 & 92,20 & 52,17 & 1,6466 & 11,32 & 4,00 & 7,15 & 22,47 \\
\hline Trema micrantha (L.) Blume & 49 & 85,20 & 39,13 & 0,2897 & 10,47 & 3,00 & 1,26 & 14,73 \\
\hline Andradea floribunda Allemão & 9 & 15,70 & 30,43 & 2,2705 & 1,92 & 2,33 & 9,85 & 14,11 \\
\hline Annona cacans Warm. & 24 & 41,70 & 47,83 & 0,7911 & 5,13 & 3,67 & 3,43 & 12,23 \\
\hline Astrocaryum aculeatissimum (Schott) Burret & 22 & 38,30 & 60,87 & 0,4648 & 4,70 & 4,67 & 2,02 & 11,38 \\
\hline Guapira opposita (Vell.) Reitz & 17 & 29,60 & 52,17 & 0,7485 & 3,63 & 4,00 & 3,25 & 10,88 \\
\hline Sparattosperma leucanthum (Vell.) K. Schum. & 16 & 27,80 & 34,78 & 0,8759 & 3,42 & 2,67 & 3,80 & 9,89 \\
\hline Helicostylis tomentosa (Poepp. \& Endl.) Rusby & 16 & 27,80 & 43,48 & 0,6794 & 3,42 & 3,33 & 2,95 & 9,70 \\
\hline Guapira areolata (Heimerl) Lundell & 18 & 31,30 & 43,48 & 0,5750 & 3,85 & 3,33 & 2,50 & 9,67 \\
\hline Cordia sellowiana Cham. & 9 & 15,70 & 34,78 & 0,9749 & 1,92 & 2,67 & 4,23 & 8,82 \\
\hline Cabralea canjerana (Vell.) Mart. & 6 & 10,40 & 21,74 & 1,1032 & 1,28 & 1,67 & 4,79 & 7,74 \\
\hline Ficus gomelleira Kunth. \& Bouché & 1 & 1,70 & 4,35 & 1,6288 & 0,21 & 0,33 & 7,07 & 7,62 \\
\hline Actinostemon verticillatus (Klotzsch) Baill. & 16 & 27,80 & 34,78 & 0,2556 & 3,42 & 2,67 & 1,11 & 7,19 \\
\hline Cupania racemosa (Vell.) Radlk. & 7 & 12,20 & 26,09 & 0,7389 & 1,50 & 2,00 & 3,21 & 6,70 \\
\hline Virola gardneri (A.DC.) Warb. & 8 & 13,90 & 17,39 & 0,5076 & 1,71 & 1,33 & 2,20 & 5,25 \\
\hline Eriotheca pentaphylla (Vell.) K. Schum. & 3 & 5,20 & 13,04 & 0,8148 & 0,64 & 1,00 & 3,54 & 5,18 \\
\hline Siparuna reginae (Tul.) A.DC. & 8 & 13,90 & 30,43 & 0,2330 & 1,71 & 2,33 & 1,01 & 5,05 \\
\hline Tetrastylidium grandifolium (Baill.) Sleumer & 3 & 5,20 & 13,04 & 0,6275 & 0,64 & 1,00 & 2,72 & 4,36 \\
\hline Micropholis crassipedicellata (Mart. \& Eichler ex Miq.) Pierre & 2 & 3,50 & 8,70 & 0,7107 & 0,43 & 0,67 & 3,08 & 4,18 \\
\hline Casearia aff. sylvestris Sw. & 7 & 12,20 & 21,74 & 0,2190 & 1,50 & 1,67 & 0,95 & 4,11 \\
\hline Pouteria guianensis Aubl. & 5 & 8,70 & 21,74 & 0,2203 & 1,07 & 1,67 & 0,96 & 3,69 \\
\hline Sorocea guilleminiana Gaudich. & 7 & 12,20 & 21,74 & 0,1096 & 1,50 & 1,67 & 0,48 & 3,64 \\
\hline Didymopanax morototoni (Aubl.) Decne. \& Planch. & 4 & 7,00 & 17,39 & 0,2660 & 0,85 & 1,33 & 1,15 & 3,34 \\
\hline Pouteria reticulata (Engl.) Eyma & 4 & 7,00 & 17,39 & 0,2439 & 0,85 & 1,33 & 1,06 & 3,25 \\
\hline Aspidosperma discolor A.DC. & 5 & 8,70 & 21,74 & 0,1123 & 1,07 & 1,67 & 0,49 & 3,22 \\
\hline Guatteria latifolia (Mart.) R.E. Fries & 5 & 8,70 & 17,39 & 0,1166 & 1,07 & 1,33 & 0,51 & 2,91 \\
\hline Lecythis lurida (Miers) S.A. Mori & 4 & 7,00 & 17,39 & 0,1418 & 0,85 & 1,33 & 0,62 & 2,80 \\
\hline Casearia sylvestris $\mathrm{Sw}$ & 4 & 7,00 & 17,39 & 0,1363 & 0,85 & 1,33 & 0,59 & 2,78 \\
\hline Garcinia gardneriana Miers ex Planch. \& Triana & 5 & 8,70 & 17,39 & 0,0772 & 1,07 & 1,33 & 0,34 & 2,74 \\
\hline Cupania sp.1 & 5 & 8,70 & 17,39 & 0,0575 & 1,07 & 1,33 & 0,25 & 2,65 \\
\hline Chrysophyllum gonocarpum (Mart. \& Eichler) Engl. & 3 & 5,20 & 13,04 & 0,2197 & 0,64 & 1,00 & 0,95 & 2,59 \\
\hline Martiodendron mediterraneum (Mart. ex Benth.) Koeppen & 1 & 1,70 & 4,35 & 0,4283 & 0,21 & 0,33 & 1,86 & 2,41 \\
\hline Phyllostemonodaphne geminiflor (Nees) Kosterm. & 3 & 5,20 & 13,04 & 0,1610 & 0,64 & 1,00 & 0,70 & 2,34 \\
\hline Matayba aff. juglandifolia Radlk. & 4 & 7,00 & 17,39 & 0,0247 & 0,85 & 1,33 & 0,11 & 2,30 \\
\hline Myrtaceae sp.14 & 4 & 7,00 & 13,04 & 0,0862 & 0,85 & 1,00 & 0,37 & 2,23 \\
\hline Casearia arborea (Rich.) Urb. & 3 & 5,20 & 13,04 & 0,1353 & 0,64 & 1,00 & 0,59 & 2,23 \\
\hline
\end{tabular}




\begin{tabular}{|c|c|c|c|c|c|c|c|c|}
\hline Espécies & $\mathbf{N}$ & DA & FA & DoA & DR & Fr & DoR & VI \\
\hline Ecclinusa ramiflora Mart. & 3 & 5,20 & 13,04 & 0,1327 & 0,64 & 1,00 & 0,58 & 2,22 \\
\hline Lauraceae sp.1 & 3 & 5,20 & 13,04 & 0,1262 & 0,64 & 1,00 & 0,55 & 2,19 \\
\hline Casearia sp. & 2 & 3,50 & 4,35 & 0,3252 & 0,43 & 0,33 & 1,41 & 2,17 \\
\hline Ocotea schottii (Meisn.) Mez & 2 & 3,50 & 8,70 & 0,2413 & 0,43 & 0,67 & 1,05 & 2,14 \\
\hline Vernonia aff .pedunculata DC. & 3 & 5,20 & 8,70 & 0,1870 & 0,64 & 0,67 & 0,81 & 2,12 \\
\hline Protium heptaphyllum (Aubl.) Marchand & 2 & 3,50 & 8,70 & 0,2266 & 0,43 & 0,67 & 0,98 & 2,08 \\
\hline Inga thibaudiana $\mathrm{DC}$. & 3 & 5,20 & 13,04 & 0,0418 & 0,64 & 1,00 & 0,18 & 1,82 \\
\hline Simaba floribunda A.St.-Hil. & 2 & 3,50 & 8,70 & 0,1666 & 0,43 & 0,67 & 0,72 & 1,82 \\
\hline Jacaranda aff. obovata Cham. & 3 & 5,20 & 13,04 & 0,0399 & 0,64 & 1,00 & 0,17 & 1,81 \\
\hline Vernonia discolor Less. & 6 & 10,40 & 4,35 & 0,0446 & 1,28 & 0,33 & 0,19 & 1,81 \\
\hline Copaifera trapezifolia Desf. & 1 & 1,70 & 4,35 & 0,2865 & 0,21 & 0,33 & 1,24 & 1,79 \\
\hline Guarea guidonia (L.) Sleumer & 3 & 5,20 & 8,70 & 0,1044 & 0,64 & 0,67 & 0,45 & 1,76 \\
\hline Brosimum guianense (Aubl.) Huber & 3 & 5,20 & 8,70 & 0,0881 & 0,64 & 0,67 & 0,38 & 1,69 \\
\hline Bocagea aff. viridis A.St.-Hil. & 2 & 3,50 & 8,70 & 0,1363 & 0,43 & 0,67 & 0,59 & 1,69 \\
\hline Manilkara aff. bella Monach. & 1 & 1,70 & 4,35 & 0,2537 & 0,21 & 0,33 & 1,10 & 1,65 \\
\hline Pogonophora schomburgkiana Miers ex Benth. & 2 & 3,50 & 4,35 & 0,2044 & 0,43 & 0,33 & 0,89 & 1,65 \\
\hline Jacaranda puberula Cham. & 2 & 3,50 & 8,70 & 0,1114 & 0,43 & 0,67 & 0,48 & 1,58 \\
\hline Inga edulis Mart. & 2 & 3,50 & 8,70 & 0,0546 & 0,43 & 0,67 & 0,24 & 1,33 \\
\hline Apocynaceae sp. & 2 & 3,50 & 8,70 & 0,0518 & 0,43 & 0,67 & 0,22 & 1,32 \\
\hline Guarea macrophylla Vahl & 2 & 3,50 & 8,70 & 0,0360 & 0,43 & 0,67 & 0,16 & 1,25 \\
\hline Duguetia pohliana Mart. & 2 & 3,50 & 8,70 & 0,0303 & 0,43 & 0,67 & 0,13 & 1,23 \\
\hline Aniba firmula (Nees \& Mart. ex Nes) Mez & 2 & 3,50 & 8,70 & 0,0250 & 0,43 & 0,67 & 0,11 & 1,20 \\
\hline Cordia trichoclada DC. & 2 & 3,50 & 8,70 & 0,0129 & 0,43 & 0,67 & 0,06 & 1,15 \\
\hline Inga capitata Desv. & 2 & 3,50 & 8,70 & 0,0107 & 0,43 & 0,67 & 0,05 & 1,14 \\
\hline Chamaecrista ensiformis (Vell.) H.S. Irwin \& Barnaby & 2 & 3,50 & 8,70 & 0,0107 & 0,43 & 0,67 & 0,05 & 1,14 \\
\hline Parinari excelsa Sabine & 1 & 1,70 & 4,35 & 0,1313 & 0,21 & 0,33 & 0,57 & 1,12 \\
\hline Mollinedia argyrogyna Perkins & 1 & 1,70 & 4,35 & 0,1313 & 0,21 & 0,33 & 0,57 & 1,12 \\
\hline Tovomita glazioviana Engl. & 3 & 5,20 & 4,35 & 0,0196 & 0,64 & 0,33 & 0,08 & 1,06 \\
\hline Myrtaceae sp.12 & 1 & 1,70 & 4,35 & 0,1109 & 0,21 & 0,33 & 0,48 & 1,03 \\
\hline Indeterminada sp.3 & 1 & 1,70 & 4,35 & 0,1033 & 0,21 & 0,33 & 0,45 & 1,00 \\
\hline Licaria $\mathrm{sp}$. & 1 & 1,70 & 4,35 & 0,1011 & 0,21 & 0,33 & 0,44 & 0,99 \\
\hline Pera heteranthera (Schrank) I.M. Jonhst. & 1 & 1,70 & 4,35 & 0,1003 & 0,21 & 0,33 & 0,44 & 0,98 \\
\hline Tovomitopsis paniculata Planch. \& Triana & 1 & 1,70 & 4,35 & 0,0691 & 0,21 & 0,33 & 0,30 & 0,85 \\
\hline Mollinedia aff. glabra (Spreng.) Perkins & 1 & 1,70 & 4,35 & 0,0679 & 0,21 & 0,33 & 0,29 & 0,84 \\
\hline Cecropia glazioui Snethl. & 2 & 3,50 & 4,35 & 0,0179 & 0,43 & 0,33 & 0,08 & 0,84 \\
\hline Myrtaceae sp.4 & 1 & 1,70 & 4,35 & 0,0631 & 0,21 & 0,33 & 0,27 & 0,82 \\
\hline Agonandra aff. fluminensis Rizzini \& Ochioni & 1 & 1,70 & 4,35 & 0,0493 & 0,21 & 0,33 & 0,21 & 0,76 \\
\hline Guatteria aff. mexiae R. E. Fries & 1 & 1,70 & 4,35 & 0,0467 & 0,21 & 0,33 & 0,20 & 0,75 \\
\hline Hirtella aff. hispidula Miq. & 1 & 1,70 & 4,35 & 0,0350 & 0,21 & 0,33 & 0,15 & 0,70 \\
\hline Eugenia jurujubensis Kiaersk. & 1 & 1,70 & 4,35 & 0,0242 & 0,21 & 0,33 & 0,10 & 0,65 \\
\hline Hyeronima alchorneoides Allemão & 1 & 1,70 & 4,35 & 0,0231 & 0,21 & 0,33 & 0,10 & 0,65 \\
\hline Brosimum aff. glaziovii Taub. & 1 & 1,70 & 4,35 & 0,0197 & 0,21 & 0,33 & 0,09 & 0,63 \\
\hline Myrcia tingens $\mathrm{O}$. Berg & 1 & 1,70 & 4,35 & 0,0181 & 0,21 & 0,33 & 0,08 & 0,63 \\
\hline Pera glabrata (Schott) Baill. & 1 & 1,70 & 4,35 & 0,0168 & 0,21 & 0,33 & 0,07 & 0,62 \\
\hline Myrtaceae sp.13 & 1 & 1,70 & 4,35 & 0,0165 & 0,21 & 0,33 & 0,07 & 0,62 \\
\hline Anaxagorea dolichocarpa Sprague \& Sandwith & 1 & 1,70 & 4,35 & 0,0162 & 0,21 & 0,33 & 0,07 & 0,62 \\
\hline Indeterminada sp.6 & 1 & 1,70 & 4,35 & 0,0148 & 0,21 & 0,33 & 0,06 & 0,61 \\
\hline Myrtaceae sp.10 & 1 & 1,70 & 4,35 & 0,0142 & 0,21 & 0,33 & 0,06 & 0,61 \\
\hline Chionanthus mandioccanus (Eichler) Lozano \& Fuentes & 1 & 1,70 & 4,35 & 0,0139 & 0,21 & 0,33 & 0,06 & 0,61 \\
\hline Macrotorus utriculatus Perkins & 1 & 1,70 & 4,35 & 0,0137 & 0,21 & 0,33 & 0,06 & 0,61 \\
\hline Bathysa mendoncaei K. Schum. & 1 & 1,70 & 4,35 & 0,0134 & 0,21 & 0,33 & 0,06 & 0,61 \\
\hline Indeterminada sp.1 & 1 & 1,70 & 4,35 & 0,0121 & 0,21 & 0,33 & 0,05 & 0,60 \\
\hline Alchornea triplinervia (Spreng.) Müll. Arg. & 1 & 1,70 & 4,35 & 0,0118 & 0,21 & 0,33 & 0,05 & 0,60 \\
\hline Eugenia oblongata $\mathrm{O}$. Berg & 1 & 1,70 & 4,35 & 0,0111 & 0,21 & 0,33 & 0,05 & 0,60 \\
\hline Ocotea dispersa (Nees) Mez & 1 & 1,70 & 4,35 & 0,0103 & 0,21 & 0,33 & 0,04 & 0,59 \\
\hline Cupania aff. revoluta Radlk. & 1 & 1,70 & 4,35 & 0,0099 & 0,21 & 0,33 & 0,04 & 0,59 \\
\hline Ocotea odorifera (Vell.) Rohwer & 1 & 1,70 & 4,35 & 0,0094 & 0,21 & 0,33 & 0,04 & 0,59 \\
\hline
\end{tabular}




\begin{tabular}{|c|c|c|c|c|c|c|c|c|}
\hline Espécies & $\mathbf{N}$ & DA & FA & DoA & DR & $\mathbf{F r}$ & DoR & VI \\
\hline Myrtaceae sp. 15 & 1 & 1,70 & 4,35 & 0,0094 & 0,21 & 0,33 & 0,04 & 0,59 \\
\hline Swartzia apetala var. glabra (Vogel) R.S. Cowan & 1 & 1,70 & 4,35 & 0,0087 & 0,21 & 0,33 & 0,04 & 0,58 \\
\hline Rubiaceae & 1 & 1,70 & 4,35 & 0,0083 & 0,21 & 0,33 & 0,04 & 0,58 \\
\hline Xylopia sericeaa A.St.-Hil. & 1 & 1,70 & 4,35 & 0,0077 & 0,21 & 0,33 & 0,03 & 0,58 \\
\hline Endlicheria glomerata $\mathrm{Mez}$ & 1 & 1,70 & 4,35 & 0,0075 & 0,21 & 0,33 & 0,03 & 0,58 \\
\hline Guarea aff. kunthiana A. Juss. & 1 & 1,70 & 4,35 & 0,0058 & 0,21 & 0,33 & 0,03 & 0,57 \\
\hline Ocotea laxa (Nees) Mez & 1 & 1,70 & 4,35 & 0,0058 & 0,21 & 0,33 & 0,03 & 0,57 \\
\hline Adenocalyma subsessilifolium DC. & 1 & 1,70 & 4,35 & 0,0054 & 0,21 & 0,33 & 0,02 & 0,57 \\
\hline Myrtaceae sp.9 & 1 & 1,70 & 4,35 & 0,0054 & 0,21 & 0,33 & 0,02 & 0,57 \\
\hline Miconia calvescens Schrank \& Mart. ex DC. & 1 & 1,70 & 4,35 & 0,0051 & 0,21 & 0,33 & 0,02 & 0,57 \\
\hline Trichilia sp. 2 & 1 & 1,70 & 4,35 & 0,0048 & 0,21 & 0,33 & 0,02 & 0,57 \\
\hline Lauraceae sp.2 & 1 & 1,70 & 4,35 & 0,0037 & 0,21 & 0,33 & 0,02 & 0,56 \\
\hline Indeterminada sp.5 & 1 & 1,70 & 4,35 & 0,0036 & 0,21 & 0,33 & 0,02 & 0,56 \\
\hline Myrtaceae sp.16 & 1 & 1,70 & 4,35 & 0,0034 & 0,21 & 0,33 & 0,01 & 0,56 \\
\hline
\end{tabular}

Tabela 3 - Parâmetros fitossociológicos das espécies amostradas no Fragmento III na Reserva Biológica de Poço das Antas, RJ, ordenadas segundo o valor de importância (VI), sendo $\mathrm{N}=$ número de indivíduos; $\mathrm{DA}=$ densidade absoluta $(\mathrm{N} / \mathrm{ha}) ; \mathrm{FA}=$ freqüência absoluta $(\%)$; DoA = dominância absoluta $\left(\mathrm{m}^{2} / \mathrm{ha}\right)$; $\mathrm{DR}=$ densidade relativa $(\%) ; \mathrm{FR}=$ frequiência relativa $(\%)$; DoR= dominância relativa $(\%)$.

\begin{tabular}{|c|c|c|c|c|c|c|c|c|}
\hline Espécies & $\mathbf{N}$ & DA & FA & DoA & DR & $\mathbf{F r}$ & DoR & VI \\
\hline Senefeldera verticillata (Vell.) Croizat & 242 & 372,30 & 96,15 & 5,3081 & 22,74 & 4,77 & 17,19 & 44,70 \\
\hline Anaxagorea dolichocarpa Sprague \& Sandwicth & 97 & 149,20 & 92,31 & 0,9426 & 9,12 & 4,58 & 3,05 & 16,75 \\
\hline Actinostemon verticillatus (Klotzch) Baill. & 78 & 120,00 & 76,92 & 0,9019 & 7,33 & 3,82 & 2,92 & 14,07 \\
\hline Mabea piriri Aubl. & 48 & 73,80 & 53,85 & 1,5429 & 4,51 & 2,67 & 5,00 & 12,18 \\
\hline Faramea truncata DC. & 57 & 87,70 & 73,08 & 0,5824 & 5,36 & 3,63 & 1,89 & 10,87 \\
\hline Helicostylis tomentosa (Poepp. \& Endl.) Rusby & 33 & 50,80 & 73,08 & 0,8765 & 3,10 & 3,63 & 2,84 & 9,57 \\
\hline Ecclinusa ramiflora Mart. & 25 & 38,50 & 53,85 & 0,5646 & 2,35 & 2,67 & 1,83 & 6,85 \\
\hline Pterocarpus rohrii Vahl & 6 & 9,20 & 19,23 & 1,5606 & 0,56 & 0,95 & 5,05 & 6,57 \\
\hline Guapira opposita (Vell.) Reitz & 19 & 29,20 & 57,69 & 0,5447 & 1,79 & 2,86 & 1,76 & 6,41 \\
\hline Astrocaryum aculeatissimum (Schott) Burret & 22 & 33,80 & 50,00 & 0,2396 & 2,07 & 2,48 & 0,78 & 5,32 \\
\hline Cabralea canjerana (Vell.) Mart. & 8 & 12,30 & 26,92 & 0,9577 & 0,75 & 1,34 & 3,10 & 5,19 \\
\hline Pseudopiptadenia contorta (DC.) G.P.Lewis \& M.P.Lima & 8 & 12,30 & 19,23 & 0,9367 & 0,75 & 0,95 & 3,03 & 4,74 \\
\hline Virola gardneri (A.DC.) Warb. & 12 & 18,50 & 30,77 & 0,4668 & 1,13 & 1,53 & 1,51 & 4,17 \\
\hline Martiodendron mediterraneum (Mart. ex Benth.) Koeppen & 7 & 10,80 & 23,08 & 0,6245 & 0,66 & 1,15 & 2,02 & 3,82 \\
\hline Bathysa mendoncaei K. Schum. & 18 & 27,70 & 30,77 & 0,1814 & 1,69 & 1,53 & 0,59 & 3,81 \\
\hline Eriotheca pentaphylla (Vell.) K. Schum. & 8 & 12,30 & 23,08 & 0,5863 & 0,75 & 1,15 & 1,90 & 3,80 \\
\hline Rinorea guianensis Aubl. & 12 & 18,50 & 38,46 & 0,2323 & 1,13 & 1,91 & 0,75 & 3,79 \\
\hline Vernonia discolor Less. & 8 & 12,30 & 15,38 & 0,7013 & 0,75 & 0,76 & 2,27 & 3,79 \\
\hline Brosimum guianense (Aubl.) Huber & 12 & 18,50 & 46,15 & 0,1005 & 1,13 & 2,29 & 0,33 & 3,74 \\
\hline Lecythis lurida (Miers) S. A. Mori & 6 & 9,20 & 23,08 & 0,6231 & 0,56 & 1,15 & 2,02 & 3,73 \\
\hline Simarouba amara A.St.-Hil. & 5 & 7,70 & 19,23 & 0,6659 & 0,47 & 0,95 & 2,16 & 3,58 \\
\hline Aparisthmium cordatum (A. Juss.) Baill. & 21 & 32,30 & 15,38 & 0,1588 & 1,97 & 0,76 & 0,51 & 3,25 \\
\hline Annona cacans Warm. & 4 & 6,20 & 15,38 & 0,6496 & 0,38 & 0,76 & 2,10 & 3,24 \\
\hline Chrysophyllum gonocarpum (Mart. \& Eichler) Engl. & 9 & 13,80 & 26,92 & 0,2952 & 0,85 & 1,34 & 0,96 & 3,14 \\
\hline Andradea floribunda Allemão & 2 & 3,10 & 7,69 & 0,7842 & 0,19 & 0,38 & 2,54 & 3,11 \\
\hline Micropholis crassipedicellata (Mart. \& Eichler ex Miq. Pierre & 3 & 4,60 & 11,54 & 0,6509 & 0,28 & 0,57 & 2,11 & 2,96 \\
\hline Swartzia apetala var. glabra (Vogel) R. S. Cowan & 10 & 15,40 & 34,62 & 0,0832 & 0,94 & 1,72 & 0,27 & 2,93 \\
\hline Guapira areolata (Heimerl) Lundell & 9 & 13,80 & 30,77 & 0,1675 & 0,85 & 1,53 & 0,54 & 2,91 \\
\hline Tapirira guianensis Aubl. & 3 & 4,60 & 11,54 & 0,5617 & 0,28 & 0,57 & 1,82 & 2,67 \\
\hline Pouteria guianensis Aubl. & 3 & 4,60 & 11,54 & 0,5408 & 0,28 & 0,57 & 1,75 & 2,61 \\
\hline Tetraplandra leandri Baill. & 9 & 13,80 & 19,23 & 0,1942 & 0,85 & 0,95 & 0,63 & 2,43 \\
\hline Pouteria bangii (Rusby) T. D. Penn. & 7 & 10,80 & 15,38 & 0,3048 & 0,66 & 0,76 & 0,99 & 2,41 \\
\hline Tetrastylidium grandifolium (Baill.) Sleumer & 5 & 7,70 & 15,38 & 0,3517 & 0,47 & 0,76 & 1,14 & 2,37 \\
\hline Faramea multiflora A. Rich. ex DC. & 9 & 13,80 & 26,92 & 0,0511 & 0,85 & 1,34 & 0,17 & 2,35 \\
\hline
\end{tabular}




\begin{tabular}{|c|c|c|c|c|c|c|c|c|}
\hline Espécies & $\mathbf{N}$ & DA & FA & DoA & DR & Fr & DoR & VI \\
\hline Pogonophora schomburgkiana Miers ex Benth. & 7 & 10,80 & 15,38 & 0,2521 & 0,66 & 0,76 & 0,82 & 2,24 \\
\hline Siparuna reginae (Tul) A.DC. & 6 & 9,20 & 23,08 & 0,1401 & 0,56 & 1,15 & 0,45 & 2,16 \\
\hline Ocotea schottii (Meisn.) Mez & 5 & 7,70 & 19,23 & 0,2046 & 0,47 & 0,95 & 0,66 & 2,09 \\
\hline Brosimum sp. & 8 & 12,30 & 19,23 & 0,1115 & 0,75 & 0,95 & 0,36 & 2,07 \\
\hline Tovomita glazioviana Engl. & 7 & 10,80 & 23,08 & 0,0806 & 0,66 & 1,15 & 0,26 & 2,06 \\
\hline Rubiaceae sp. & 7 & 10,80 & 23,08 & 0,0578 & 0,66 & 1,15 & 0,19 & 1,99 \\
\hline Garcinia gardneriana Miers ex Planch. \& Triana & 6 & 9,20 & 23,08 & 0,0772 & 0,56 & 1,15 & 0,25 & 1,96 \\
\hline Cordia sellowiana Cham. & 3 & 4,60 & 11,54 & 0,2955 & 0,28 & 0,57 & 0,96 & 1,81 \\
\hline Simaba floribunda A.St.-Hil. & 4 & 6,20 & 11,54 & 0,2193 & 0,38 & 0,57 & 0,71 & 1,66 \\
\hline Sorocea guilleminiana Gaudich. & 6 & 9,20 & 15,38 & 0,0827 & 0,56 & 0,76 & 0,27 & 1,60 \\
\hline Myrtaceae sp.9 & 4 & 6,20 & 15,38 & 0,1191 & 0,38 & 0,76 & 0,39 & 1,53 \\
\hline Balizia pedicellaris (DC.) Barnaby \& J. W. Grimes & 1 & 1,50 & 3,85 & 0,3722 & 0,09 & 0,19 & 1,21 & 1,49 \\
\hline Erythroxylum cuspidifolium Mart. & 5 & 7,70 & 15,38 & 0,0629 & 0,47 & 0,76 & 0,20 & 1,44 \\
\hline Eugenia oblongata $\mathrm{O}$. Berg & 4 & 6,20 & 15,38 & 0,0817 & 0,38 & 0,76 & 0,26 & 1,40 \\
\hline Coussarea sp. & 4 & 6,20 & 15,38 & 0,0481 & 0,38 & 0,76 & 0,16 & 1,30 \\
\hline Guatteria latifolia (Mart.) R. E. Fries & 4 & 6,20 & 15,38 & 0,0446 & 0,38 & 0,76 & 0,14 & 1,28 \\
\hline Lauraceae sp.1 & 5 & 7,70 & 11,54 & 0,0589 & 0,47 & 0,57 & 0,19 & 1,23 \\
\hline Roupala aff. sculpta Sleumer & 4 & 6,20 & 11,54 & 0,0803 & 0,38 & 0,57 & 0,26 & 1,21 \\
\hline Cupania furfuracea Radlk. & 3 & 4,60 & 11,54 & 0,0995 & 0,28 & 0,57 & 0,32 & 1,18 \\
\hline Myrtaceae sp.12 & 3 & 4,60 & 11,54 & 0,0958 & 0,28 & 0,57 & 0,31 & 1,16 \\
\hline Copaifera trapezifolia Hayne & 2 & 3,10 & 7,69 & 0,1662 & 0,19 & 0,38 & 0,54 & 1,11 \\
\hline Calyptranthes grandifolia $\mathrm{O}$. Berg & 4 & 6,20 & 11,54 & 0,0478 & 0,38 & 0,57 & 0,15 & 1,10 \\
\hline Bocagea aff. viridis A.St.-Hil. & 2 & 3,10 & 7,69 & 0,1630 & 0,19 & 0,38 & 0,53 & 1,10 \\
\hline Jacaranda puberula Cham. & 2 & 3,10 & 7,69 & 0,1620 & 0,19 & 0,38 & 0,52 & 1,09 \\
\hline Ficus gomelleira Kunth. \& Bouché & 2 & 3,10 & 7,69 & 0,1607 & 0,19 & 0,38 & 0,52 & 1,09 \\
\hline Myrtaceae sp.11 & 4 & 6,20 & 11,54 & 0,0360 & 0,38 & 0,57 & 0,12 & 1,07 \\
\hline Licaria sp. & 2 & 3,10 & 7,69 & 0,1497 & 0,19 & 0,38 & 0,48 & 1,05 \\
\hline Ocotea dispersa (Nees) Mez & 2 & 3,10 & 7,69 & 0,1486 & 0,19 & 0,38 & 0,48 & 1,05 \\
\hline Micropholis gardneriana (A.DC.) Pierre & 3 & 4,60 & 11,54 & 0,0471 & 0,28 & 0,57 & 0,15 & 1,01 \\
\hline Aspidosperma discolor A.DC. & 3 & 4,60 & 11,54 & 0,0458 & 0,28 & 0,57 & 0,15 & 1,00 \\
\hline Ocotea aff. silvestris Vattimo & 3 & 4,60 & 7,69 & 0,1004 & 0,28 & 0,38 & 0,33 & 0,99 \\
\hline Protium spruceanum (Benth.) Engl. & 1 & 1,50 & 3,85 & 0,2121 & 0,09 & 0,19 & 0,69 & 0,97 \\
\hline Matayba aff. juglandifolia Radkl. & 3 & 4,60 & 11,54 & 0,0282 & 0,28 & 0,57 & 0,09 & 0,95 \\
\hline Guarea macrophylla Vahl & 3 & 4,60 & 11,54 & 0,0253 & 0,28 & 0,57 & 0,08 & 0,94 \\
\hline Micropholis guyanensis (A.DC.) Pierre & 2 & 3,10 & 7,69 & 0,1063 & 0,19 & 0,38 & 0,34 & 0,91 \\
\hline Copaifera langsdorfii Desf. & 2 & 3,10 & 7,69 & 0,1062 & 0,19 & 0,38 & 0,34 & 0,91 \\
\hline Marlierea dimorpha Berg & 3 & 4,60 & 11,54 & 0,0119 & 0,28 & 0,57 & 0,04 & 0,89 \\
\hline Guatteria aff. ferruginea A.St.-Hil. & 3 & 4,60 & 7,69 & 0,0705 & 0,28 & 0,38 & 0,23 & 0,89 \\
\hline Astronium graveolens Jacq. & 2 & 3,10 & 7,69 & 0,0874 & 0,19 & 0,38 & 0,28 & 0,85 \\
\hline Hirtella angustifolia Schott ex Spreng. & 2 & 3,10 & 7,69 & 0,0863 & 0,19 & 0,38 & 0,28 & 0,85 \\
\hline Mollinedia aff. heteranthera Perkins & 1 & 1,50 & 3,85 & 0,1690 & 0,09 & 0,19 & 0,55 & 0,83 \\
\hline Ocotea odorifera (Vell.) Rohwer & 2 & 3,10 & 7,69 & 0,0790 & 0,19 & 0,38 & 0,26 & 0,83 \\
\hline Couepia venosa Prance & 2 & 3,10 & 3,85 & 0,1360 & 0,19 & 0,19 & 0,44 & 0,82 \\
\hline Guatteria xylopioides R.E. Fr. & 2 & 3,10 & 7,69 & 0,0528 & 0,19 & 0,38 & 0,17 & 0,74 \\
\hline Chamaecrista ensiformis (Vell.) H.S. Irwin \& Barnaby & 2 & 3,10 & 7,69 & 0,0449 & 0,19 & 0,38 & 0,15 & 0,72 \\
\hline Licania arianeae Prance & 2 & 3,10 & 7,69 & 0,0428 & 0,19 & 0,38 & 0,14 & 0,71 \\
\hline Heisteria perianthomega (Vell.) Sleumer & 2 & 3,10 & 7,69 & 0,0311 & 0,19 & 0,38 & 0,10 & 0,67 \\
\hline Eugenia sp. & 2 & 3,10 & 7,69 & 0,0251 & 0,19 & 0,38 & 0,08 & 0,65 \\
\hline Peritassa aff. campestris (Cambess.) A.C.Sm. & 2 & 3,10 & 7,69 & 0,0246 & 0,19 & 0,38 & 0,08 & 0,65 \\
\hline Casearia aff. sylvestris $\mathrm{Sw}$. & 2 & 3,10 & 7,69 & 0,0225 & 0,19 & 0,38 & 0,07 & 0,64 \\
\hline Exostyles venusta Schott ex Spreng. & 2 & 3,10 & 7,69 & 0,0197 & 0,19 & 0,38 & 0,06 & 0,63 \\
\hline Eugenia microcarpa O. Berg & 2 & 3,10 & 7,69 & 0,0151 & 0,19 & 0,38 & 0,05 & 0,62 \\
\hline Myrtaceae sp.8 & 2 & 3,10 & 7,69 & 0,0118 & 0,19 & 0,38 & 0,04 & 0,61 \\
\hline Casearia arborea (Rich.) Urb. & 2 & 3,10 & 7,69 & 0,0090 & 0,19 & 0,38 & 0,03 & 0,60 \\
\hline Chionanthus mandioccanus (Eichler) Lozano \& Fuentes & 1 & 1,50 & 3,85 & 0,0887 & 0,09 & 0,19 & 0,29 & 0,57 \\
\hline Himatanthus aff. lancifolius (Müll. Arg.) Woodson & 2 & 3,10 & 3,85 & 0,0494 & 0,19 & 0,19 & 0,16 & 0,54 \\
\hline
\end{tabular}




\begin{tabular}{|c|c|c|c|c|c|c|c|c|}
\hline Espécies & $\mathbf{N}$ & DA & FA & DoA & DR & Fr & DoR & VI \\
\hline Strychnos sp. & 1 & 1,50 & 3,85 & 0,0767 & 0,09 & 0,19 & 0,25 & 0,53 \\
\hline Vernonia aff. pedunculata DC. & 2 & 3,10 & 3,85 & 0,0470 & 0,19 & 0,19 & 0,15 & 0,53 \\
\hline Mollinedia sp. & 1 & 1,50 & 3,85 & 0,0755 & 0,09 & 0,19 & 0,24 & 0,53 \\
\hline Psychotria carthaginensis Jacq. & 1 & 1,50 & 3,85 & 0,0725 & 0,09 & 0,19 & 0,23 & 0,52 \\
\hline Manilkara aff. bella Monach. & 1 & 1,50 & 3,85 & 0,0725 & 0,09 & 0,19 & 0,23 & 0,52 \\
\hline Cupania sp.2 & 1 & 1,50 & 3,85 & 0,0708 & 0,09 & 0,19 & 0,23 & 0,51 \\
\hline Sclerolobium beaurepairei Harms & 1 & 1,50 & 3,85 & 0,0634 & 0,09 & 0,19 & 0,21 & 0,49 \\
\hline Trichilia silvatica DC. & 1 & 1,50 & 3,85 & 0,0606 & 0,09 & 0,19 & 0,20 & 0,48 \\
\hline Mollinedia argyrogyna Perkins & 1 & 1,50 & 3,85 & 0,0564 & 0,09 & 0,19 & 0,18 & 0,47 \\
\hline Mollinedia oligantha Perkins & 1 & 1,50 & 3,85 & 0,0518 & 0,09 & 0,19 & 0,17 & 0,45 \\
\hline Xylopia sericea A.St.-Hil. & 1 & 1,50 & 3,85 & 0,0503 & 0,09 & 0,19 & 0,16 & 0,45 \\
\hline Guarea guidonia (L.) Sleumer & 2 & 3,10 & 3,85 & 0,0178 & 0,19 & 0,19 & 0,06 & 0,44 \\
\hline Moldenhawera polysperma (Vell.) Stellfeld & 1 & 1,50 & 3,85 & 0,0445 & 0,09 & 0,19 & 0,14 & 0,43 \\
\hline Buchenavia kleinii Exell & 1 & 1,50 & 3,85 & 0,0418 & 0,09 & 0,19 & 0,14 & 0,42 \\
\hline Cupania racemosa (Vell.) Radlk. & 1 & 1,50 & 3,85 & 0,0374 & 0,09 & 0,19 & 0,12 & 0,41 \\
\hline Toulicia laevigata Radlk. & 1 & 1,50 & 3,85 & 0,0345 & 0,09 & 0,19 & 0,11 & 0,40 \\
\hline Sapotaceae sp. 1 & 1 & 1,50 & 3,85 & 0,0321 & 0,09 & 0,19 & 0,10 & 0,39 \\
\hline Naucleopsis mello-barretoi (Standl) C.C. Berg & 1 & 1,50 & 3,85 & 0,0309 & 0,09 & 0,19 & 0,10 & 0,38 \\
\hline Psychotria sp. & 1 & 1,50 & 3,85 & 0,0305 & 0,09 & 0,19 & 0,10 & 0,38 \\
\hline Indeterminada sp. 2 & 1 & 1,50 & 3,85 & 0,0305 & 0,09 & 0,19 & 0,10 & 0,38 \\
\hline Casearia sylvestris $\mathrm{Sw}$. & 1 & 1,50 & 3,85 & 0,0302 & 0,09 & 0,19 & 0,10 & 0,38 \\
\hline Myrtaceae sp.17 & 1 & 1,50 & 3,85 & 0,0298 & 0,09 & 0,19 & 0,10 & 0,38 \\
\hline Cybianthus aff. brasiliensis (Mez) G. Agostini & 1 & 1,50 & 3,85 & 0,0294 & 0,09 & 0,19 & 0,10 & 0,38 \\
\hline Aniba firmula (Nees \& C. Mart.) Mez & 1 & 1,50 & 3,85 & 0,0279 & 0,09 & 0,19 & 0,09 & 0,38 \\
\hline Parinari excelsa Sabine & 1 & 1,50 & 3,85 & 0,0272 & 0,09 & 0,19 & 0,09 & 0,37 \\
\hline Casearia commersoniana Cambess. & 1 & 1,50 & 3,85 & 0,0268 & 0,09 & 0,19 & 0,09 & 0,37 \\
\hline Peschiera aff. fuchsiaefolia (A.DC.) Miers & 1 & 1,50 & 3,85 & 0,0258 & 0,09 & 0,19 & 0,08 & 0,37 \\
\hline Albizia polycephala (Benth.) Killip ex Record & 1 & 1,50 & 3,85 & 0,0237 & 0,09 & 0,19 & 0,08 & 0,36 \\
\hline Inga leptantha Benth. & 1 & 1,50 & 3,85 & 0,0233 & 0,09 & 0,19 & 0,08 & 0,36 \\
\hline Duguetia pohliana Mart. & 1 & 1,50 & 3,85 & 0,0227 & 0,09 & 0,19 & 0,07 & 0,36 \\
\hline Cecropia glazioui Snethl. & 1 & 1,50 & 3,85 & 0,0214 & 0,09 & 0,19 & 0,07 & 0,35 \\
\hline Myrtaceae sp.2 & 1 & 1,50 & 3,85 & 0,0207 & 0,09 & 0,19 & 0,07 & 0,35 \\
\hline Esenbeckia grandiflora Mart. & 1 & 1,50 & 3,85 & 0,0189 & 0,09 & 0,19 & 0,06 & 0,35 \\
\hline Myrtaceae sp.10 & 1 & 1,50 & 3,85 & 0,0180 & 0,09 & 0,19 & 0,06 & 0,34 \\
\hline Pouteria reticulata (Engl.) Eyma & 1 & 1,50 & 3,85 & 0,0177 & 0,09 & 0,19 & 0,06 & 0,34 \\
\hline Myrtaceae sp.13 & 1 & 1,50 & 3,85 & 0,0168 & 0,09 & 0,19 & 0,05 & 0,34 \\
\hline Indeterminada sp.7 & 1 & 1,50 & 3,85 & 0,0152 & 0,09 & 0,19 & 0,05 & 0,33 \\
\hline Inga thibaudiana DC. & 1 & 1,50 & 3,85 & 0,0144 & 0,09 & 0,19 & 0,05 & 0,33 \\
\hline Solanum swartzianum Roem. \& Schult. & 1 & 1,50 & 3,85 & 0,0136 & 0,09 & 0,19 & 0,04 & 0,33 \\
\hline Tapirira aff. obtusa (Benth.) D. J. Mitch. & 1 & 1,50 & 3,85 & 0,0133 & 0,09 & 0,19 & 0,04 & 0,33 \\
\hline Miconia cinnamomifolia (DC.) Naudin & 1 & 1,50 & 3,85 & 0,0121 & 0,09 & 0,19 & 0,04 & 0,32 \\
\hline Maytenus communis Reissek & 1 & 1,50 & 3,85 & 0,0114 & 0,09 & 0,19 & 0,04 & 0,32 \\
\hline Calyptranthes brasiliensis Spreng. & 1 & 1,50 & 3,85 & 0,0114 & 0,09 & 0,19 & 0,04 & 0,32 \\
\hline Macrotorus utriculatus Perkins & 1 & 1,50 & 3,85 & 0,0114 & 0,09 & 0,19 & 0,04 & 0,32 \\
\hline Ocotea divaricata (Nees) Mez & 1 & 1,50 & 3,85 & 0,0107 & 0,09 & 0,19 & 0,03 & 0,32 \\
\hline Indeterminada sp.4 & 1 & 1,50 & 3,85 & 0,0102 & 0,09 & 0,19 & 0,03 & 0,32 \\
\hline Ocotea laxa (Nees) Mez & 1 & 1,50 & 3,85 & 0,0087 & 0,09 & 0,19 & 0,03 & 0,31 \\
\hline Eugenia excelsa $\mathrm{O}$. Berg & 1 & 1,50 & 3,85 & 0,0079 & 0,09 & 0,19 & 0,03 & 0,31 \\
\hline Indeterminada sp. 8 & 1 & 1,50 & 3,85 & 0,0075 & 0,09 & 0,19 & 0,02 & 0,31 \\
\hline Swartzia apetala var. apetala R. S. Cowan & 1 & 1,50 & 3,85 & 0,0074 & 0,09 & 0,19 & 0,02 & 0,31 \\
\hline Astronium sp. & 1 & 1,50 & 3,85 & 0,0068 & 0,09 & 0,19 & 0,02 & 0,31 \\
\hline Myrtaceae sp.5 & 1 & 1,50 & 3,85 & 0,0059 & 0,09 & 0,19 & 0,02 & 0,30 \\
\hline Trichilia aff. luciae Barreiros & 1 & 1,50 & 3,85 & 0,0058 & 0,09 & 0,19 & 0,02 & 0,30 \\
\hline Erythroxylum citrifolium A.St.-Hil. & 1 & 1,50 & 3,85 & 0,0051 & 0,09 & 0,19 & 0,02 & 0,30 \\
\hline Trichilia sp. 1 & 1 & 1,50 & 3,85 & 0,0048 & 0,09 & 0,19 & 0,02 & 0,30 \\
\hline Myrcia aff. fallax (Rich.) DC. & 1 & 1,50 & 3,85 & 0,0046 & 0,09 & 0,19 & 0,02 & 0,30 \\
\hline
\end{tabular}




\begin{tabular}{|c|c|c|c|c|c|c|c|c|}
\hline Espécies & $\mathbf{N}$ & DA & FA & DoA & DR & Fr & DoR & VI \\
\hline Chrysobalanaceae sp. & 1 & 1,50 & 3,85 & 0,0045 & 0,09 & 0,19 & 0,01 & 0,30 \\
\hline Duguetia sessilis (Vell.) Maas & 1 & 1,50 & 3,85 & 0,0041 & 0,09 & 0,19 & 0,01 & 0,30 \\
\hline Myrtaceae sp.14 & 1 & 1,50 & 3,85 & 0,0037 & 0,09 & 0,19 & 0,01 & 0,30 \\
\hline Myrtaceae sp.6 & 1 & 1,50 & 3,85 & 0,0031 & 0,09 & 0,19 & 0,01 & 0,30 \\
\hline Maytenus aff. lancifolius (Thonn.) Loes. & 1 & 1,50 & 3,85 & 0,003 & 0,09 & 0,19 & 0,01 & 0,29 \\
\hline
\end{tabular}

A ocorrência de $S$. verticillata de forma bem destacada nos trechos estudados e de forma bem menos expressiva ou rara em outras áreas da Reserva (Guedes-Bruni 1998; Neves 1999), na mata da Rebio União (Rodrigues 2004), na mata de Paraíso (Kurtz 2000), na mata do Carvão (Silva \& Nascimento 2001) e na mata de Linhares (Peixoto \& Gentry, 1990) ou mesmo ausente na floresta de morrote de Pariquera-Açu (Sztutman \& Rodrigues 2002), de Magé (Guedes 1988) e na mata da Fazenda Biovert (Borém \& Oliveira-Filho 2002) sugere que as comunidades avaliadas neste estudo apresentam as condições mais adequadas para o bom desenvolvimento e regeneração desta espécie. Trata-se de espécie lactescente, o que poderia lhe conferir uma proteção relativa contra herbívoros (Cabral 2001), podendo estar mais habilitada a ocupar tanto os ambientes de borda, mais sujeitos à herbivoria, como as regiões mais internas dos fragmentos (Cadenasso \& Picket 2000). No entanto, sugere-se que a abundância desta espécie tenha fortes relações com as condições do ambiente, como sugerido por Brown (1984). Estes locais por apresentarem os ambientes preferenciais desta espécie, poderiam ocasionar sua ocorrência em grande abundância.

A análise do tamanho das populações indica altos percentuais de espécies com baixa densidade para as três áreas $(82,8 \%, 72,8 \%$ e $68,2 \%$ para as áreas I, II e III respectivamente), sendo aqui consideradas como espécies com baixa densidade aquelas que se apresentam com três ou menos indivíduos. Embora a presença de espécies em baixa densidade seja uma característica das comunidades florestais tropicais (Hubbell \& Foster 1986) ocorre, porém, que as espécies que naturalmente assim se apresentam, são mais propensas à extinção local, devido às variações ambientais e demográficas, problemas genéticos e eventos naturais (Shafer 1981 apud Nascimento et al. 1999; Gilpin \& Soulé 1986). Kageyama (1987 apud Tabanez et al. 1997) considera o número de 50 indivíduos e Kageyama \& Gandara (1998) estabelecem o número de 500 indivíduos como a população mínima viável para a manutenção a curto e a longo prazo de uma população em um dado local. Para as comunidades levantadas estima-se, respectivamente, uma densidade total de 6,13 e 15 indivíduos por hectare para aquelas espécies que apareceram no limite da raridade (um indivíduo) nas unidades amostrais estudadas (Martins 1991).

Somente as espécies que alcançaram no trecho levantado quantitativos maiores que 8 (área I) e 4 (área II e III) indivíduos e que 75 (área I), 38 (área II) e 33 (área III) indivíduos teriam uma população local total estimada maior ou igual a 50 e a 500 indivíduos tendo então, probabilidades mais altas de se manterem a curto e a longo prazo na comunidade. Isto significa que $6,2 \%$ e $1,5 \%$ das espécies da comunidade I, $27,1 \%$ e $1,8 \%$ das espécies da área II e $31,7 \%$ e $3,9 \%$ das espécies da comunidade III satisfazem os critérios acima mencionados, sugerindo um alto grau de risco de extinção local para essas espécies (Tab. 4). Os autores desconhecem, até o momento, a existência de trabalhos sobre tamanho mínimo de população para qualquer uma das espécies presentes nas três comunidades estudadas. Vale ressaltar que apenas parte dos indivíduos de uma população constitui a população apta a reprodução, sendo este valor bastante pequeno em relação ao tamanho total da população local (Forman 1999). Operando no sentido de minimizar o efeito dos baixos valores encontrados, poderiam estar à disposição espacial do grupo 
Tabela 4 - Número e percentual de espécies por tamanho estimado da população a partir de $5 \mathrm{~cm}$ de DAP, para três fragmentos florestais amostrados na Reserva Biológica de Poço das Antas, RJ.

\begin{tabular}{c|ccc|ccc}
\hline \multirow{2}{*}{ Fragmento } & \multicolumn{3}{|c|}{ número de espécies } & \multicolumn{3}{c}{ percentual de espécies } \\
\cline { 2 - 7 } & $<\mathbf{5 0}$ ind. & $\geqq \mathbf{5 0}$ ind. & $\geqq \mathbf{5 0 0}$ ind. & $<\mathbf{5 0}$ ind. & $\geqq \mathbf{5 0}$ ind. $\geqq \mathbf{5 0 0}$ ind. \\
\hline I & 60 & 4 & 1 & 93,7 & 6,2 & 1,5 \\
II & 78 & 29 & 2 & 72,8 & 27,1 & 1,8 \\
III & 103 & 48 & 6 & 68,2 & 31,7 & 3,9 \\
\hline
\end{tabular}

de oito fragmentos, a distância entre estes, bem como o tamanho e composição de cada uma destas unidades. A disposição espacial garante a existência de pequenas distâncias entre o grupo de fragmentos e estas, por suas extensões possibilitam, para várias de suas espécies, o intercâmbio de pólen e sementes, atenuando, assim, a probabilidade de risco de extinção local das espécies. $\mathrm{O}$ fato destas unidades serem compostas de fragmentos de diferentes tamanhos, sugere que estes possam apresentar diferentes condições ambientais, proporcionando assim ambientes preferenciais para uma gama diversificada de espécies (Brown, 1984). Isto permite que as espécies apresentem diferentes padrões de abundância e possam ocorrer em diferentes estágios de desenvolvimento, em cada uma das unidades.

A distribuição das classes de diâmetro de todos os indivíduos amostrados aponta uma provável ausência de dificuldades para a regeneração dos elementos das três comunidades, pela forte entrada de elementos jovens nestas áreas. Uma análise da estrutura populacional de espécies abundantes e importantes para cada uma das comunidades (Fig. 5) indica que estas possuem padrões de distribuição bem distintos, apresentando a maioria, sérios problemas para sua continuidade na comunidade, desde que não haja regeneração. Isto é bem evidenciado para as espécies do fragmento I e II e em menor grau para o fragmento III. Possivelmente, estes resultados possam estar associados à ocorrência e intensidade dos fatores de perturbação que incidiram sobre cada uma das áreas estudadas. Não desconsiderando que na análise de distribuição de indivíduos por classe de diâmetro, o comportamento reprodutivo da espécie e a tolerância ecológica de seus indivíduos jovens influenciam amplamente os resultados (Richards 1981).

É importante assinalar que muitas das espécies que são comuns a mais de uma área podem apresentar indivíduos em diferentes fases de desenvolvimento, a exemplo de $M$. crassipedicellata que ocorre somente com indivíduos nas maiores classes de diâmetro na área II e indivíduos nas classes intermediária e de maior diâmetro na área III. Desta forma isto possibilitaria a continuidade da espécie na região e possivelmente em ambas as áreas, considerando que a distância de aproximadamente $400 \mathrm{~m}$ que as separa não representaria um obstáculo aos possíveis agentes de polinização e dispersão. Não descarta-se, no entanto, a necessidade de conhecimentos sobre a biologia destas espécies e as influências dos efeitos da fragmentação sobre as espécies e as comunidades, na análise mais detalhada dos resultados.

Para o índice de diversidade ( $\left.\mathrm{H}^{\prime}\right)$ foram obtidos os valores de 3,02 nats/ind. (área I), 3,90 nats/ind. (área II) e 3,65 nats/ind. (área III) e para equabilidade (J) 0,73, 0,83 e 0,73 respectivamente. Estes valores são próximos ou ligeiramente menores aos encontrados em outros trechos da Reserva por Neves (1999), em trecho com 20 anos $\left(H^{\prime}=3,24\right.$ nats/ind. e $\mathrm{J}=0,79$ ) e com 40 anos de regeneração ( $\mathrm{H}^{\prime}=$ 3,78 nats/ind. e $\mathrm{J}=0,81$ ) e por Guedes-Bruni (1998) em floresta de baixada (H'=3,98 nats/ ind. e $\mathrm{J}=0,87$ ) e em floresta de morrote $\left(\mathrm{H}^{\prime}=\right.$ 4,55 nats/ind. e $\mathrm{J}=0,89$ ), onde apenas o índice de diversidade encontrado para as florestas de morrote se distancia dos demais. Os resultados 
apontam tratar-se de três áreas de elevada diversidade, considerando o critério de inclusão adotado (DAP $\geq 5 \mathrm{~cm}$ ), bem como a área das unidades amostrais inferior a 1 ha. Nestes ambientes, perturbações naturais como queda de árvores e conseqüente surgimento de clareiras e, perturbações antrópicas, aqui
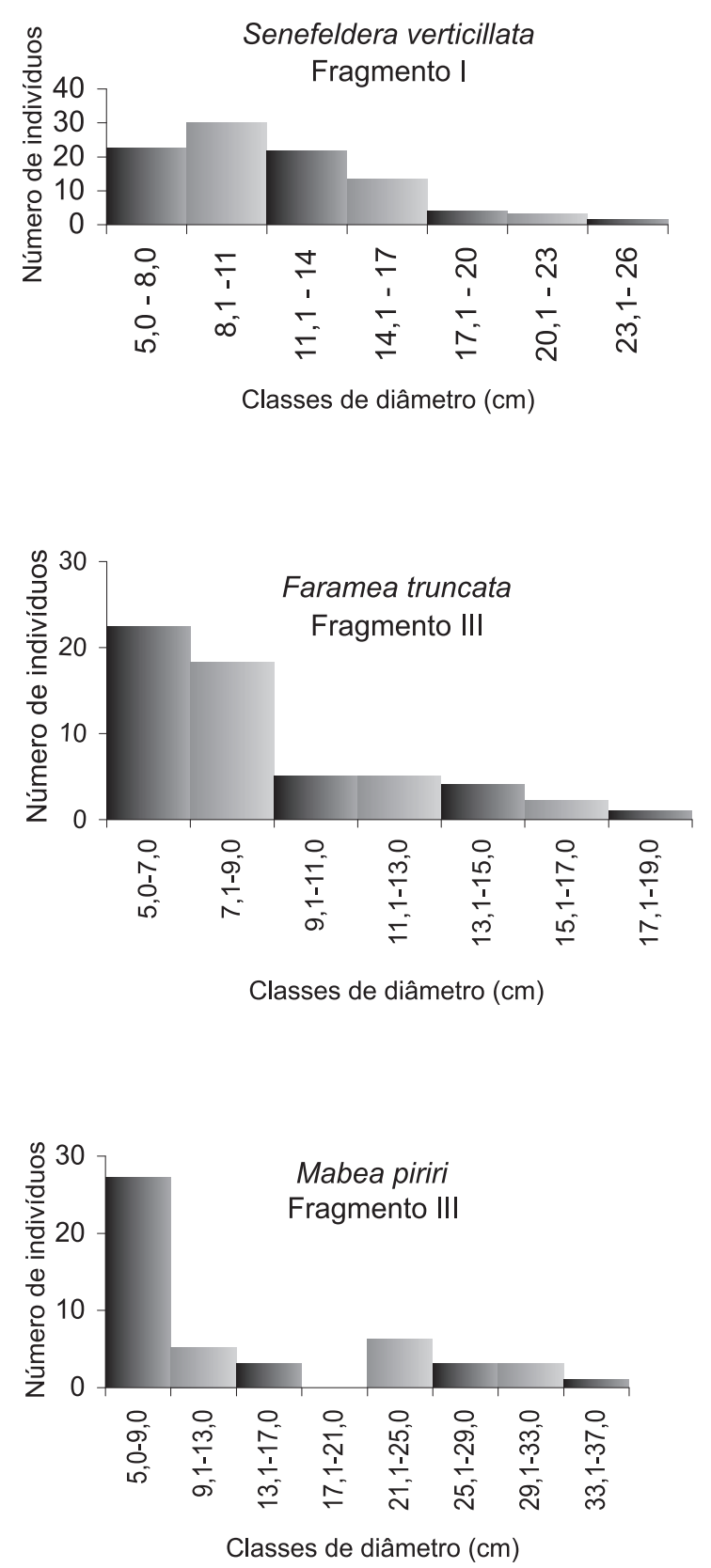

configuradas por incêndios, têm promovido heterogeneidade ambiental, o que poderia permitir a coexistência de espécies com diferentes demandas por luz, nutrientes, temperatura e umidade (Denslow 1980). Porém, embora detenham níveis altos de diversidade de espécies, esta por si só, não garante a
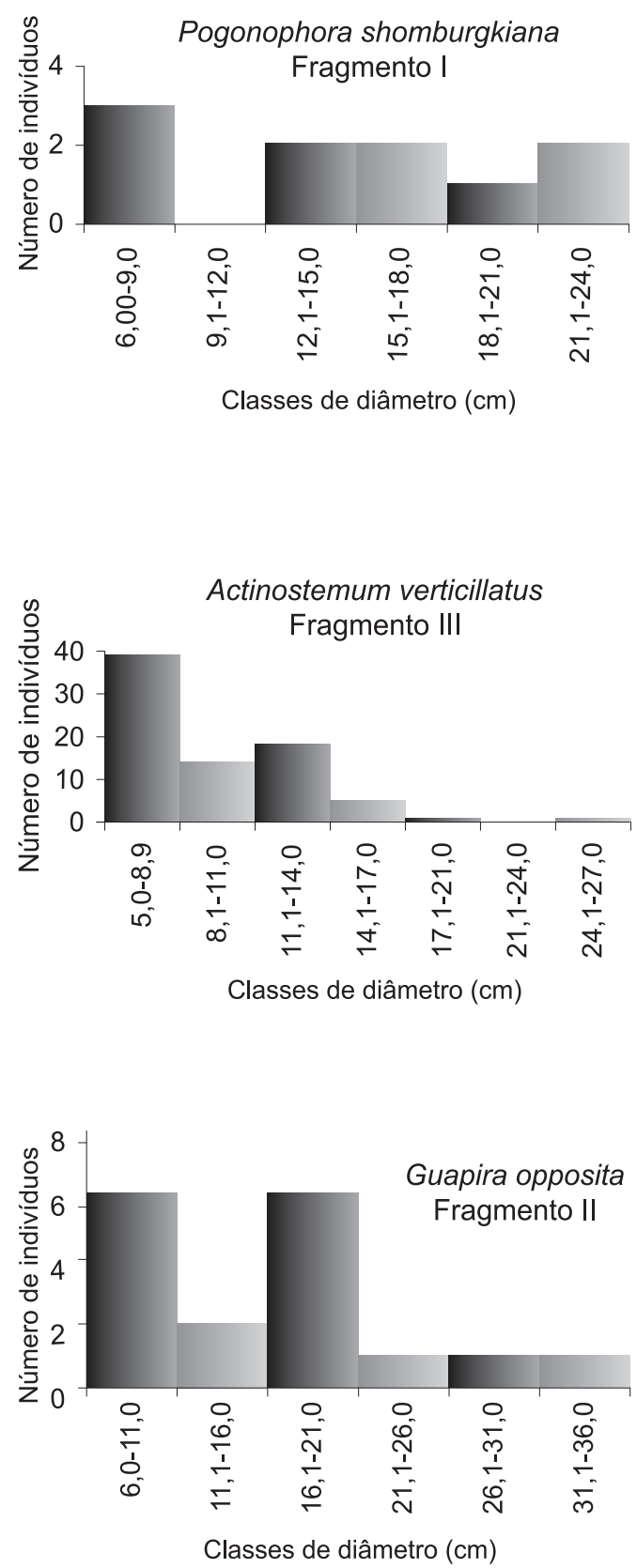

Figura 5 - Distribuição de freqüência das classes de diâmetro dos indivíduos de espécies abundantes e importantes em três fragmentos florestais amostrados na Reserva Biológica de Poço das Antas, RJ. 
resiliência, a longo prazo, destes remanescentes e para isto é importante que todas as populações tenham um tamanho adequado que lhes permita resistir a eventos estocásticos (doenças, tempestades etc).

Esses dados sugerem que, apesar dos danos causados nas duas últimas décadas por incêndios e da pequena extensão destes fragmentos, estas áreas parecem estar conseguindo resistir a estas perturbações. Possivelmente, para isto muito tem contribuído a proximidade entre estas comunidades e demais unidades que compõem o conjunto de oito fragmentos, propiciando o intercâmbio de propágulos entre as áreas e, desta forma, a diversidade de espécies que em graus diferenciados contribuem na composição estrutural. Tal fato sugere também que o banco de sementes do solo tem, até o momento, reagido bem à intensidade e duração destes incêndios. No entanto, como bem apontado por Wilcove et al. (1986), nenhuma área protegida está imune aos efeitos ecológicos provenientes de áreas fora de seus limites. Atividades agrícolas, pequenos núcleos urbanos etc em regiões limítrofes a áreas protegidas podem representar um aumento na população de algumas espécies. E estas podem se mostrar muito mais agressivas e competitivas do que as espécies presentes na unidade resguardada.

Portanto, conclui-se que o conjunto de variações estruturais analisados, parece estar associado mais à ocorrência, amplitude e intensidade diferentes das perturbações a que estes fragmentos estão expostos, do que às diferenças em tamanho dos fragmentos. As variações observadas nos padrões de abundância e importância das espécies nas diferentes áreas reforçam a relevância deste conjunto de fragmentos para a permanência de determinadas espécies na região.

\section{Agradecimentos}

Os autores agradecem à equipe da Reserva Biológica de Poço das Antas pela utilização da infra-estrutura da Reserva. Aos colegas Haroldo C. de Lima, Sebastião S.
Neto, José Fernando A. Baumgratz, Alexandre Quinet, Ronaldo Marquete, Cyl Farney C. de Sá, Nilda M. F. da Silva, Ângela S. da F. Vaz, Genise V. Freire, Ariane L. Peixoto, Marli P. Morim e à Dra. Graziela M. Barroso (in memorian) pelo auxílio na identificação do material botânico. A Petrobras pelo suporte financeiro ao Programa Mata Atlântica/JBRJ.

\section{REFERÊNCIAS BIBLIOGRÁFICAS}

Aizen, M. A. \& Feinsinger, P. 1994. Forest fragmentation, pollination, and plant reproduction in a chaco dry forest, Argentina. Ecology 75(2): 330-351.

Bawa, K. S. 1990. Plant-pollinator interactions in tropical forest. Annals Review in Ecology and Systematics 21: 399-422.

Borém, R. A. T. \& Ramos, D. P. 2001. Estrutura fitossociológica da comunidade arbórea de uma toposseqüência alterada de uma área de floresta atlântica, no município de Silva Jardim-RJ. Revista Árvore 25(1): 131-140.

\& Oliveira-Filho, A. T. 2002. Fitossociologia do estrato arbóreo em uma toposseqüência alterada de mata atlântica, no município de Silva Jardim-RJ, Brasil. Revista Árvore 26(6): 727-742.

Brown, J. H. 1984. On the relation between abundance and distribution of species. The American Naturalist 124: 255-279.

Cabral, B. C. 2001. Efeito de borda sobre herbivoria foliar por insetos de um fragmento de Mata Atlântica em Rio das Ostras - RJ. Dissertação de Mestrado. Universidade do Norte Fluminense, Campo dos Goytacazes, 60p.

Cadenasso, M. L. \& Pickett, S. T. A. 2000. Effect of edge structure on the flux of species into forest interiors. Conservation Biology 15(1): 91-97.

Castellani, T. T. 1986. Sucessão secundária inicial em mata tropical semi-decídua, após perturbação por fogo. Dissertação de Mestrado. Universidade Estadual de Campinas, Campinas, $180 \mathrm{p}$. 
Cronquist, A. 1988. The evolution and classification of flowering plants. The New York Botanical Garden, New York, 556 p.

Denslow, J. S. 1980. Gap partitioning among tropical rain forest trees. Biotropica 12 supplement: 47-55.

Ewel, J. 1977. Differences between wet and dry successional tropical ecosystems. Geo-Eco-Trop. 1: 103-117.

Felfili, J. M. \& Silva-Junior, M. C. 1988. Distribuição dos diâmetros numa faixa de cerrado na Fazenda Água Limpa (FAL) em Brasília-DF. Acta Botanica Brasilica 2(1-2): 85-105.

Forman, R. T. T. 1999. Land Mosaics - the ecology of landscapes and regions. Cambridge University Press, Cambridge, $632 \mathrm{p}$.

Fundação S.O.S. Mata Atlântica. 2002. Atlas da evolução dos remanescentes florestais e ecossistemas associados no domínio da Mata Atlântica no período de 1995-2000. São Paulo, SOS Mata Atlântica/INPE/ISA.

Gandolfi, S., Leitão Filho, H. F., Bezerra, C. L. F. 1995. Levantamento florístico e caráter sucessional das espécies arbustivo-arbóreas de uma floresta mesófila semidecídua no município de Garulhos, SP. Revista Brasileira de Biologia 55(4): 753-767.

Gilpin, M. E. \& Soulè, M. E. 1986. Minimum viable populations: processes of species extinction. In: Soulè, M. E. (Ed.) Conservation biology: the science of scarcity and diversity. Sinauer Press, Massachusetts. Pp. 19-35.

Guedes, R. R. 1988. Composição florística e estrutura de um trecho de mata perturbada de baixada no município de Magé, Rio de Janeiro. Arquivos do Jardim Botânico do Rio de Janeiro 29: 155-200.

Guedes-Bruni, R. R. 1998. Composição, estrutura e similaridade florística de dossel em seis unidades fisionômica de Mata Atlântica no Rio de Janeiro. Tese de Doutorado. Universidade de São Paulo, São Paulo, 206p.
Hubbell, S. P. \& Foster, R. B. 1986. Commonness and rarity in a neotropical forest. In: Soulè, M. E. (ed.). Conservation biology: the science of scarcity and diversity. Sinauer Press, Massachusetts. Pp. 205-231.

Kageyama, P. Y. \& Gandara, F. B. 1998. Consequiências genéticas da fragmentação sobre populações de espécies arbóreas. Série Técnica IPEF 12(32): 65-70.

Kurtz, B. C. 2000. Composição florística e estrutura do componente arbóreo de um trecho de Mata Atlântica na Estação Ecológica Estadual do Paraíso, Cachoeiras de Macacu, Rio de Janeiro, Brasil. Rodriguésia 51(78/79): 69-111.

Laurence, W. F. 1997. Hyper-disturbed parks: edge effects and the ecology of isolated forest reserves in tropical Australia. In: Laurence, W. F. \& Bierregaard, R. O. JR. (Eds.) Tropical forest remnants: ecology, management, and conservation of fragmented communities. The University of Chicago Press, Chicago. Pp. 71-83.

Laurence, W. F.; Ferreira, L. V.; Rankin-de Marona, J. M. \& Laurence, S. G. 1998. Rain forest fragmentation and the dynamics of Amazonian tree communities. Ecology 76(6): 2032-2040.

Laurence, W. F.; Lovejoy, T. E.; Vasconcellos, H. L.; Bruna, E M.; Didham, R. K.; Stouffer, P. C.; Gascon, C.; Bierregaard, R. O.; Laurence, S. G. \& Sampaio, E. 2002. Ecosystem decay of Amazonian forest fragments: a 22-year investigation. Conservation Biology 16(3): 605-618.

Lovejoy, T. E.; Bierregaard, R. O.; Rylands, A. B.; Malcon, J. R.; Quintela, C. E.; Harper, L. H.; Brown, K. S.; Powell, A. H.; Powell, G. V. N.; Schubart, H. O. R. \& Hays, M. B. 1986. Edge and other effects of isolation on Amazon forest fragments. In: Soulé, M. E. (ed.). Conservation biology, the science of scarcity and diversity. Massachusetts, Sinauer Press. Pp. 257-285. 
Magurran, A. E. 1988. Ecological diversity and its measurement. Croom Helm Limited, London, 179p.

Martins, F. R. 1991. Estrutura de uma floresta mesófila. Editora da Universidade Estadual de Campinas, Campinas, 246 p.

Meffe, G. K.; Carroll, C. R. \& Contributors. 1997. Principles of Conservation Biology. Sinauer Press, Massachusetts, 799p.

Mesquita, R. C. G.; Delamônica, P \& Laurence, W. F. 1999. Effect of surrounding vegetation on edge-related tree mortality in Amazonian forest fragments. Biological Conservation 91: 129-134.

Miranda, E. E. \& Coutinho, A. C. (Coord.).2004. Brasil Visto do Espaço. Campinas: Embrapa Monitoramento por Satélite. Disponível em: <http:// www.cdbrasil.cnpm.embrapa.br $>$. Acesso em: 5 jul. 2005.

Moraes, L. F. D.; Luchiari, C.; Assumpção, J. M.; Puglia-Neto, R. \& Pereira, T. S. 2002. Atlantic rainforest restoration by the Rio de Janeiro Botanic Research Institute. In: Maunder, M.; Clubbe, C.; Hankamer, C. \& Groves, M. (Eds.) Plant conservation in the tropics - perspectives and practice. The Cromwell Press Ltda, London. Pp. 151-170.

Mueller-Dombois, D. \& Ellenberg, H. 1974. Aims and methods of vegetation ecology. Ed. John Willey \& Sons, New York, 574p.

Murcia, C. 1995. Edge effects in fragmented forests: implications for conservation. Trends in Ecology and Evolution 10(2): 58-62.

Nascimento, H. E. M.; Dias, A. S.; Tabanez, A. A. J. \& Viana, V. M. 1999. Estrutura e dinâmica de populações arbóreas de um fragmento de floresta estacional semidecidual na região de Piracicaba, SP. Revista Brasileira de Biologia 59(2): 329-342.

Neves, G. M. S. 1999. Florística e estrutura da comunidade arbustivo-arbórea em dois remanescentes de Floresta Atlântica secundária - Reserva Biológica de Poço das Antas, Silva Jardim, RJ. Dissertação de Mestrado. Universidade Federal do Rio de Janeiro, Rio de Janeiro, 115p.
Peixoto, A. L \& Gentry, A. 1990. Diversidade e composição florística da mata de tabuleiro na Reserva Florestal de Linhares (Espírito Santo, Brasil). Revista Brasileira de Botânica 13: 19-25.

Pereira, T. S. \& Mantovani, W. 2001. Maturação e dispersão de Miconia cinnamomifolia (DC) Naud. na Reserva Biológica de Poço das Antas, Município de Silva Jardim, RJ, Brasil. Acta Botanica Brasilica 15(3): 335-348.

Pessoa, S. V. A. 2003. Aspectos da fragmentação em remanescentes florestais da planície costeira do estado do Rio de Janeiro. Dissertação de Mestrado. Universidade Federal Rural do Rio de Janeiro, Seropédica, 96p.

Richards, P. W. 1981. The tropical rain forest. Cambridge University Press, Cambridge, 450p.

Rodrigues, P. J. F. P. 2004. A vegetação da Reserva Biológica União e os efeitos de borada na Mata Atlântica fragmentada. Tese de Doutorado. Universidade Estadual do Norte Fluminense, Campos dos Goytacazes, 153p.

Sá, C. F. C. 2002. Regeneração de um trecho de floresta de restinga na Reserva Ecológica Estadual de Jacarepiá, Saquarema, Estado do Rio de Janeiro: II - estrato arbustivo. Rodriguésia 53(82): 5-23.

Saunders, D. A.; Hobbs, R. J. \& Margules, C. R. 1991. Biological consequences of ecosystem fragmentation: a review. Conservation Biology 5: 18-32.

Scarano, F. R.; Ribeiro, K. T.; Moraes, L. F. D. \& Lima, H. C. 1997. Plant establishment on flooded and unflooded patches of a freshwater swamp forest in southeastern Brazil. Journal of Tropical Ecology 14: 793-803.

Shepherd, G. J. 1994. FITOPAC 2, Manual do usuário. UNICAMP, Campinas.

Silva, G. C. \& Nascimento, M. T. 2001. Fitossociologia de mata sobre tabuleiros no norte do estado do Rio de Janeiro (Mata do Carvão). Revista Brasileira de Botânica 24(1): 51-62. 
Silva Matos, D. M.; Caluca, J. F. \& Souza, A. F. 1998. Consequiências da fragmentação florestal sobre a densidade e tamanho de indivíduos arbóreos na REBIO de Poço das Antas, RJ. In: IV Simpósio de Ecossistemas Brasileiros. Vol. 2. ACIESP, Águas de Lindóia. Pp. 120-125. ; Ramos, F. N.; Torres, M. C.; Souza, A. F.; Fonseca, G. D. F. M.; Siqueira, L. P.; Braz, M. I. G.; Lima, L. S. \& Portela, R. C. Q. 1998. A fragmentação florestal na Reserva Biológica de Poço das Antas (RJ): uma visão fitocêntrica. In: IV Simpósio de Ecossistemas Brasileiros. Vol. 5. ACIESP, Águas de Lindóia. Pp. 190-195.

Souza, A. F. \& Martins, F. R. 2002. Spatial distribution of an undergrowth palm in fragments of the Brazilian Atlantic Forest. Plant Ecology 164: 141-155.

Sztutman, M. \& Rodrigues, R. R. 2002. O mosaico vegetacional numa área de floresta contínua da planície litorânea, Parque Estadual da Campina do Encantado, Pariquera-Açu, SP. Revista Brasileira de Botânica 25(2): 161-176.

Tabanez, A. A. J.; Viana, V. M. \& Dias, A. S. 1997. Consequiências da fragmentação e do efeito de borda sobre a estrutura, diversidade e sustentabilidade de um fragmento de floresta de planalto. Revista Brasileira de Biologia 57(1): 47-60.

Tanizaki-Fonseca, K. \& Moulton, T. P. 2000. A fragmentação da Mata Atlântica no Estado do Rio de Janeiro e a perda da biodiversidade. In: Bergallo, H. G.; Rocha, C. F. D. da; Alves, M. A. S. \& Sluys, M. van (orgs.). A fauna ameaçada de extinção do estado do Rio de Janeiro. Ed. UERJ, Rio de Janeiro. Pp. 23-35.
Takizawa, F. H. 1995. Levantamento pedológico e zoneamento ambiental da Reserva Biológica de Poço das Antas. Monografia de graduação. Escola Superior de Agricultura Luis de Queiroz/ USP, Piracicaba, 56p.

Templeton, A. R.; Shaw, K.; Routman, E. \& Davis, S. K. 1990. The genetic consequences of habitat fragmentation. Annals of the Missouri Botanical Garden 77: 13-27.

Turner, I. M. 1996. Species loss in fragments of tropical rain forest: a review of evidence. Journal of Applied Ecology 33: 200-209.

Turner, I. M \& Collet, R. T. 1996. The conservation value of small, isolated fragments of lowland rain forest. Trends in Ecology and Evolution 11: 8.

Veloso, H. P.; Rangel Filho, A. L. R. \& Lima, J. C. A. 1991. Classificação da vegetação brasileira adaptada a um sistema universal. IBGE, Rio de Janeiro, 124p.

Vieira, C. M. \& Pessoa, S. V. A. 2001. Estrutura e composição florística do estrato herbáceo-subarbustivo de um pasto abandonado na Reserva Biológica de Poço das Antas, município de Silva Jardim, RJ. Rodriguésia 52(80): 17-29.

Wilcove, D. S.; McLellan, C. H. \& Dobson, A. P. 1986. Habitat fragmentation in the temperate zone. In: Soulè, M. E. (ed.) Conservation biology, the science of scarcity and diversity. Sinauer Press, Massachusetts. Pp. 237-256.

Williams-Linera, G. 1990. Vegetation structure and environmental conditions of forest edges in Panama. Journal of Ecology 78: 356-373. 